\title{
RHEOLOGICAL STRUCTURE OF THE EARTH'S MANTLE DERIVED FROM GLACIAL REBOUND IN LAURENTIDE
}

\author{
Masao NAKADA \\ Ocean Research Institute, the University of Tokyo, \\ Tokyo, Japan \\ (Received October 28, 1983; Revised February 13, 1984)
}

\begin{abstract}
The rheological structure of the earth's mantle was determined based on data from the postglacial isostatic adjustment in Laurentide. According to a linear analysis with a Newtonian rheology, the apparent viscosity derived from the observed relative sea level data is about ten times larger in the central part of the glaciated region than that in the surrounding region. Namely, the apparent viscosity has spatial dependence. The observed relation $\dot{\zeta} \propto \zeta^{3-4}$ in Laurentide and Fennoscandia, where $\dot{\zeta}$ and $\zeta$ respectively represent uplift rate and estimated remaining uplift, does not reflect the non-linearity of the rheological property of the earth's mantle. Rather, the observed relation $\dot{\zeta} \propto \zeta^{8-4}$ means that the lower mantle viscosity is greater than $10^{24}$ poise, regardless of Newtonian or non-Newtonian rheology.

According to the analysis for a thin channel viscosity model with a powerlaw creep rheology $\dot{\varepsilon} \propto \sigma^{8}$, where $\dot{\varepsilon}$ and $\sigma$ respectively represent strain rate and deviatoric stress, the observed relative sea level variations and free-air gravity anomalies in the glaciated region in Laurentide can be explained almost satisfactorily. The same model is also consistent with the observed relation $\dot{\zeta} \propto \zeta^{3-4}$. Our calculation therefore indicates that the viscosity of the lower mantle is so high that a thin channel viscosity model is a good approximation of the mantle flow, and that the upper mantle rheology is governed by the power-law creep law with $n=3\left(\dot{\varepsilon} \propto \sigma^{8}\right)$. The average temperature, strain rate, deviatoric stress, and apparent viscosity estimated in the present work are $1,500 \mathrm{~K}$ to $1,700 \mathrm{~K}$, $2.8 / H^{2} \mathrm{sec}^{-1}, 0.22 \mathrm{H}$ bar, and $0.04 H^{8}$ poise, respectively, where $H$ represents the thickness of the low viscosity channel in $\mathrm{cm}$. The relationship between strain rate and deviatoric stress is consistent with an extrapolation of high strain rate laboratory data.
\end{abstract}

\section{Introduction}

The viscosity of the earth's mantle is one of the most important factors governing mantle dynamics. In particular, mantle convection should have a quite different nature, depending on whether the contrast of the viscosity between upper and lower mantle is high or low. If the lower mantle has more than $10^{4}$ times the viscosity of the upper mantle, convection would be confined to the 
upper mantle (DAvis, 1977; ElSASSER et al., 1979). If the viscosity contrast is not so sharp, whole mantle convection would occur instead (DAvis, 1977; ELSASSER et al., 1979).

To determine the viscosity structure of the earth's mantle, the glacial rebound data in Laurentide have been extensively studied by WALCOTT (1972a, b, 1973, 1980), Andrews (1970a, b), Cathles (1975, 1980), Farrell and Clark (1976), Peltier and Andrews (1976), Peltier et al. (1978), Clark et al. (1978), Peltier (1976, 1980), Peltier et al. (1981), and Wu and Peltier (1982). The data have been analyzed under the assumptions of Newtonian rheology and laterally homogeneous structure. Based on his analysis, WALCOTT (1972a, 1973, 1980) suggested that most deformation associated with the postglacial relaxation occurs in the upper mantle. This idea is mathematically represented by a model with channel low viscosity layer. The thin channel model was first proposed by VAN BemMELEN and BerLAGe (1935), and later supported by TAKeUCHI and HASEGAWA (1965). On the other hand, Andrews (1970a, b). Cathles (1975), Peltier et al. (1978), Clark et al. (1978), Peltier (1976), and Wu and Peltier (1982) suggested that the lower mantle, as well as the upper mantle, has a relatively low viscosity of about $10^{22}$ poise. Such a viscosity structure corresponds to the uniform viscosity model, which was first proposed by HASKELL $(1935,1936)$.

The viscosity of the earth's mantle is also related to the dip angle of the descended slab that is dynamically supported by viscous drag. Based on the data of Wadati-Benioff zone geometry, HAGER and O'CONNELL $(1978,1979)$ maintained that the uniform viscosity model is consistent with the observed dip angles, while Yokokura (1979) used the same data to support the presence of the thin channel with low viscosity in the shallow mantle. Thus there is no consensus at present about the viscosity of the earth's mantle.

The viscosity structure also influences worldwide distribution of postglacial sea level. WALCOTT (1972a) first pointed out that the sea level change shows systematic trends near the glaciated area. Based on the uniform viscosity model with viscosity of $1 \times 10^{22}$ poise, Peltier et al. (1978) and ClARK et al. (1978) calculated more quantitatively the worldwide relative sea level pattern, and obtained the regions (I) and (II) corresponding to the postglacial rebound and submergence areas discovered by WALCOTT (1972a). However, the agreement between theory and observation is only qualitative in those calculations. Particularly significant disagreement remains in the glaciated region (I) and the peripheral region (II) in Laurentide. A further theoretical study is essential to give a better explanation of relative sea level variation in these important regions containing the greatest deformation.

Based on the analysis of sea level change in the forebulge region of Laurentide throughout the late glacial and postglacial stage, CATHLES (1975) concluded that lower mantle viscosity should be $1 \times 10^{22}$ poise. He claimed that observed late glacial peripheral uplift followed by subsidence is a phenomenon that can be explained only by a Newtonian flow with the viscosity of about $1 \times 10^{22}$ poise in 
the lower mantle. According to the calculation by Peltier et al. (1981), however, the sea level pattern in the peripheral region can be explained by higher mantle viscosity. They suggested that the relative sea level pattern in Boston and Cliton better fits the viscosity model with lower mantle viscosity greater than $1 \times 10^{23}$ poise. Deformation in the forebulge region may be seriously influenced by the history of the deglaciation, as was suggested by WALCOTT (1972b). Furthermore, eustatic sea level at the late glacial stage has an uncertainty perhaps as large as $10 \mathrm{~m}$ (ShePard, 1963; Farrbridge, 1968; Möner, 1969). This again makes it difficult to derive a definite conclusion from the data in the forebulge region. Considering all these points, the evidence suggesting lower mantle viscosity is about $1 \times 10^{22}$ poise seems inconclusive.

WeERTMAN (1970) proposed a power-law creep of the mantle rheology, based on a theoretical model of the creep mechanism associated with dislocation climb. Extensive experimental and theoretical studies on the creep mechanism by KIRBY and Raleigh (1973), Stocker and Ashby (1973), Karato (1977), Post (1977), and DURHAM and GoETze (1977) followed the prediction of WEERTMAN (1970). Unfortunately, their estimates of the rheological parameters of the mantle scatter over a fairly wide range. The strain rate strongly depends on temperature whose distribution in the earth's mantle is quite uncertain. Therefore a reliable estimate of the viscosity is not possible at the present stage.

In the analysis of glacial rebound, available information is generally classified into the following three categories: relative sea level variations derived from old beach distribution, present rates of vertical crustal movement obtained from geodetic measurement, and the present remaining uplift estimated from free-air gravity anomalies. The analysis of the Laurentide uplift is subject to the strongest restriction from relative sea level data, particularly in the glaciated region in Laurentide. There are only a few data values for vertical crustal movements in Laurentide. The free-air gravity anomalies in Laurentide compiled by WALCOTT (1970a) are well correlated with the relative sea level pattern in the glaciated region.

In this study, we first examined the postglacial relative sea level variation in and around the glaciated region of Laurentide. In this calculation, we assumed that the mantle behaves like a Newtonian fluid. In this analysis, we found that the apparent viscosity derived from the observed sea level data was about ten times larger in the central part of the glaciated region than that in the surrounding region. Namely the apparent viscosity has spatial dependence, which was qualitatively suggested by WALCOTT (1980). Next we formulated glacial isostatic adjustment assuming a power-law creep rheology based on the thin channel viscosity model. Based on this model, spatial dependence of the apparent viscosity can be theoretically explained and the observed relative sea level variations and freeair gravity anomalies in the glaciated region can be explained almost satisfactorily. 
2. Analysis for a Laterally Homogeneous Viscosity Model with a Newtonian Rheology

\subsection{The method of analysis}

The analysis of the late glacial crustal movement requires information on the ice melting history, which is largely unknown. In this section, we only consider the postglacial isostatic adjustment that is treated without explicitly referring to the ice melting history. The earth's mantle is assumed to be a Newtonian fluid whose viscosity is laterally homogeneous. The viscosity model discussed in this section is shown in Fig. 1. In this model, the top layer is an elastic plate with flexural rigidity $F$. The middle layer is composed of a Newtonian fluid with viscosity $\eta_{\mathrm{a}}$ and thickness $H$. The bottom is a semi-infinite medium with viscosity $\eta_{1}$.

We denote surface displacement by $\zeta=\zeta(x, y, t)$. Generally, $\zeta$ can be represented in the following form;

$$
\zeta(x, y, t)=\int_{-\infty}^{\infty} \int A(l, m) \exp [-f(l, m) t] \exp [i(l x+m y)] \mathrm{d} l \mathrm{~d} m,
$$

where $l$ and $m$ represent $x$ and $y$ components of wavenumbers, respectively (TAKeuCHI and Hasegawa, 1965; MCConnell, 1965, 1968; CATHLes, 1975). $A(l, m)$ is determined by the initial conditions only. The relaxation function $f(l, m)$ depends on the rheological structure of the earth's interior (TAKEUCHI and Hasegawa, 1965; McConnell, 1965, 1968; CAthles, 1975). Relaxation time $\tau_{\mathrm{r}}$ is defined by $\tau_{\mathrm{r}}=1 / f(l, m)$. For the model shown in Fig. $1, f(l, m)$ is expressed as
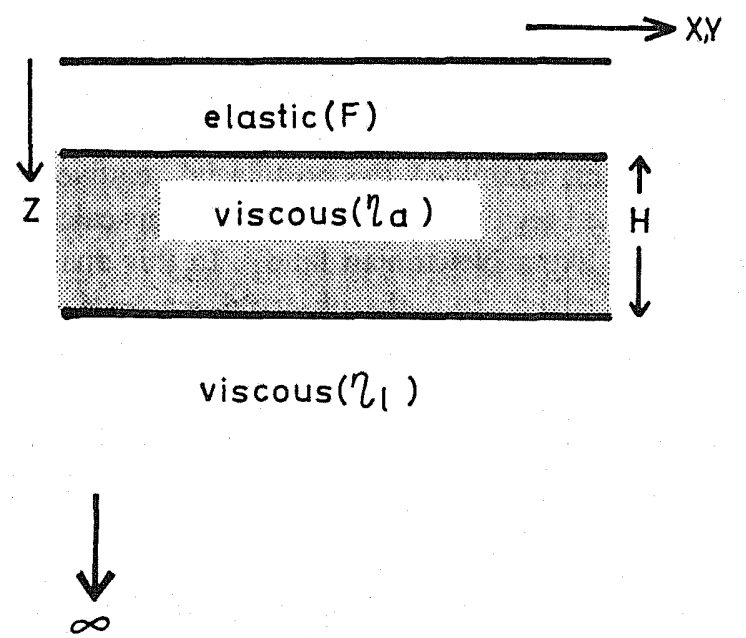

Fig. 1. Rheological structure used for analysis in this chapter. Elastic effect is represented by flexural rigidity $F$. Viscosities in the upper and lower parts are represented by $\eta_{a}$ and $\eta_{1}$, respectively. The thickness of the upper viscous layer is represented as $H$. 

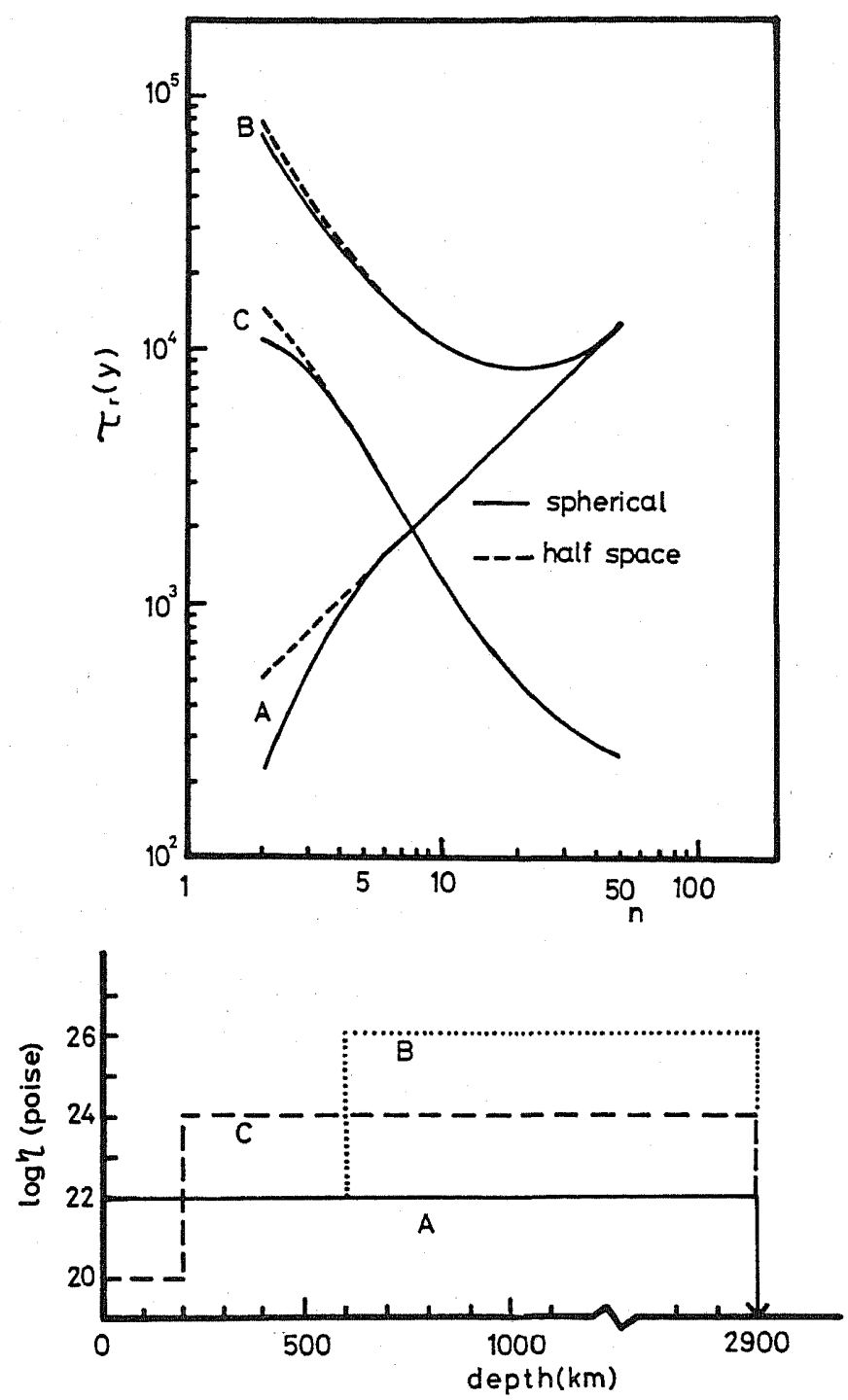

Fig. 2. Relaxation time $\tau_{\mathrm{r}}$ v.s. order number $n$ of spherical harmonics, for models $\mathrm{A}, \mathrm{B}$, and $C$. Solid and dashed lines show the results in the spherical and infinite half space earth models, respectively. When the order number, $n$, is greater than 5 , the spherical relaxation time is the same as the half space relaxation time for both models.

$$
f(l, m)=\frac{\rho g}{2 \eta_{1} k} \frac{\left(\tilde{\eta}+\tilde{\eta}^{-1}\right) C S+k H\left(\tilde{\eta}-\tilde{\eta}^{-1}\right)+S^{2}+C^{2}}{2 C S \tilde{\eta}+(1-\tilde{\eta}) k^{2} H^{2}+\tilde{\eta} S^{2}+C^{2}}\left(1+\frac{F}{\rho g} k^{4}\right),
$$

where $k=\sqrt{l^{2}+m^{2}}, \tilde{\eta}=\eta_{\mathrm{a}} / \eta_{1}, S=\sinh (k H)$ and $C=\cosh (k H)$, (CATHLES, 1975). Here $\rho$ and $g$ are density and gravitational acceleration, respectively, and are assumed in this paper to be constant for all the layers. Figure 2 shows for the 
three typical viscosity models that the relaxation time spectrum does not significantly differ between a semi-infinite half space model and a spherical earth model when the wavelength is less than $8,000 \mathrm{~km}$, that is, when the order number, $n$, is greater than 5 for the spherical harmonics. Since the wavelengths covering the glaciated and peripheral region of Laurentide are $6,000 \mathrm{~km}$ at their greatest (WALCOTT, 1972b), we may adopt a half space model for the present study.

We denote the relative displacement (relative sea level) between a past time $t_{\mathrm{p}}\left(t_{\mathrm{p}}\right.$ is negative) and the present $t=0$ as $\Delta \zeta\left(x, y, t_{\mathrm{p}}\right)$, which is defined in the following form:

$$
\Delta \zeta\left(x, y, t_{\mathrm{p}}\right)=\zeta\left(x, y, t_{\mathrm{p}}\right)-\zeta(x, y, 0) .
$$

$\Delta \zeta\left(x, y, t_{\mathrm{p}}\right)$ is transformed into the wavenumber space to give:

$$
\begin{aligned}
& \Delta \zeta\left(x, y, t_{\mathrm{p}}\right)=\int_{-\infty}^{\infty} \int B\left(l, m, t_{\mathrm{p}}\right) \exp [i(l x+m y)] \mathrm{d} / \mathrm{d} m \\
& B\left(l, m, t_{\mathrm{p}}\right)=\frac{1}{4 \pi^{2}} \int_{-\infty}^{\infty} \int \Delta \zeta\left(x, y, t_{\mathrm{p}}\right) \exp [-i(l x+m y)] \mathrm{d} x \mathrm{~d} y .
\end{aligned}
$$

Combining (2.1), (2.3), and (2.4), $A(l, m)$ is written as

$$
A(l, m)=\frac{B\left(l, m, t_{\mathrm{p}}\right)}{\exp \left[-f(l, m) t_{\mathrm{p}}\right]-1}
$$

(2.1), (2.4), and (2.5) allow us to calculate the displacement at any time from relative sea level data. The free-air gravity anomalies $\Delta g_{\mathrm{f}}$ corresponding to the present remaining uplift $\zeta(x, y, 0)$ are calculated by the following relation:

$$
\Delta g_{f}=-2 \pi G \rho \zeta(x, y, 0),
$$

where $G$ is the gravitational constant.

It is convenient to introduce the weighting function

$$
P\left(l, m, t_{\mathrm{p}}, t\right)=\frac{\exp [-f(l, m) t]}{\exp \left[-f(l, m) t_{\mathrm{p}}\right]-1} .
$$

(2.1) coupled with (2.5) and (2.7) yields an equation for the displacement at any time.

$$
\zeta(x, y, t)=\int_{-\infty}^{\infty} \int B\left(l, m, t_{\mathrm{p}}\right) P\left(l, m, t_{\mathrm{p}}, t\right) \exp [i(l x+m y)] \mathrm{d} l \mathrm{~d} m .
$$

Applying the convolution theorem to (2.8), we have the following expression for $\zeta$ :

$$
\zeta(x, y, t)=\frac{1}{4 \pi^{2}} \int_{-\infty}^{\infty} \int 4 \zeta\left(x-x^{\prime}, y-y^{\prime}, t_{\mathrm{p}}\right) p\left(x^{\prime}, y^{\prime}, t_{\mathrm{p}}, t\right) \mathrm{d} x^{\prime} \mathrm{d} y^{\prime},
$$

where $p\left(x, y, t_{\mathrm{p}}, t\right)$ is the inverse Fourier transform of $P\left(l, m, t_{\mathrm{p}}, t\right)$. With use of Eq. (2.9), $\zeta(x, y, t)$ is calculated by the convolution of $p\left(x, y, t_{\mathrm{p}}, t\right)$ and $\Delta \zeta\left(x, y, t_{\mathrm{p}}\right)$.

It is more convenient to represent the kernel $p\left(x, y, t_{\mathrm{p}}, t\right)$ with respect to the cylindrical co-ordinate system $(r, \theta)$ that is defined by $x=r \cos \theta$ and $y=r \sin \theta$, 
respectively. We define the transform co-ordinate $(k, \phi)$ in wavenumber space, as $l=k \cos \psi$ and $m=k \sin \psi$. As a result of this co-ordinate transformation, it turns out that $P\left(l, m, t_{\mathrm{p}}, t\right)$ defined by Eq. (2.7) with (2.2) does not depend on $\psi$, and $p\left(r, \theta, t_{\mathrm{p}}, t\right)$ is reduced to

$$
p\left(r, \theta, t_{\mathrm{p}}, t\right)=\int_{0}^{2 \pi} \int_{0}^{\infty} P\left(k, t_{\mathrm{p}}, t\right) \exp [i k r \cos (\theta-\phi)] k \mathrm{~d} k \mathrm{~d} \varphi^{\prime} .
$$

In the above expression, Hansen's formula

$$
\int_{0}^{2 \pi} \exp [i k r \cos (\theta-\phi)] \mathrm{d} \phi=2 \pi J_{0}(k r)
$$

may be used to estimate the $\psi$ integration, where $J_{0}(k r)$ is the zeroth order Bessel function. Therefore $p\left(r, \theta, t_{\mathrm{p}}, t\right)$ is independent of $\theta$ and expressed as

$$
p\left(r, t_{\mathrm{p}}, t\right)=2 \pi \int_{0}^{\infty} k J_{0}(k r) P\left(k, t_{\mathrm{p}}, t\right) \mathrm{d} k .
$$

This is the final expression for the kernel $p\left(r, t_{p}, t\right)$ of the convolution Eq. (2.9). With this kernel, (2.9) gives the expression for the uplift at any time, given just the differential uplift occurring between $t_{\mathrm{p}}$ and the present.

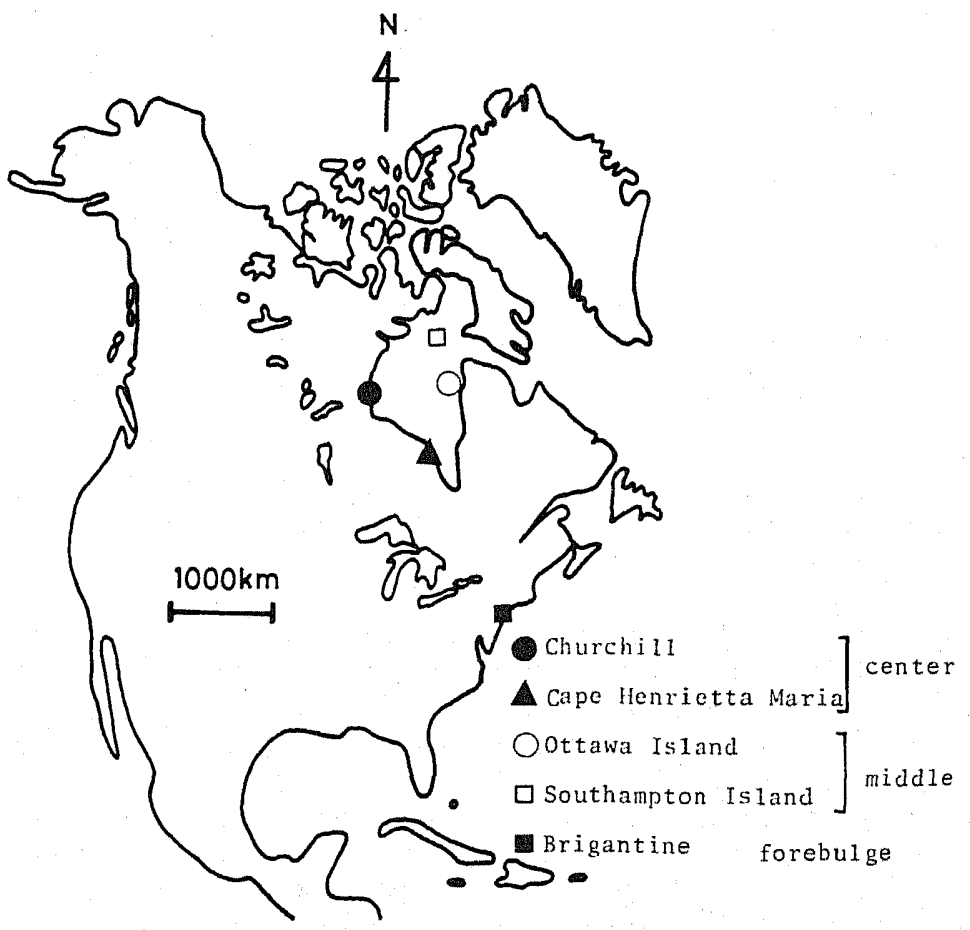

Fig. 3. Locations used in this study. 


\subsection{Results}

The theoretical displacement at any time after $t_{p}$ is calculated from the sea level change between the time $t_{\mathrm{p}}$ and the present. For the present analysis, we used the relative sea level data compiled by WaLCOTT (1972b). From the observed sea level change during the past 6,000 years, we calculated $\Delta \zeta(x, y, 4,000)$,
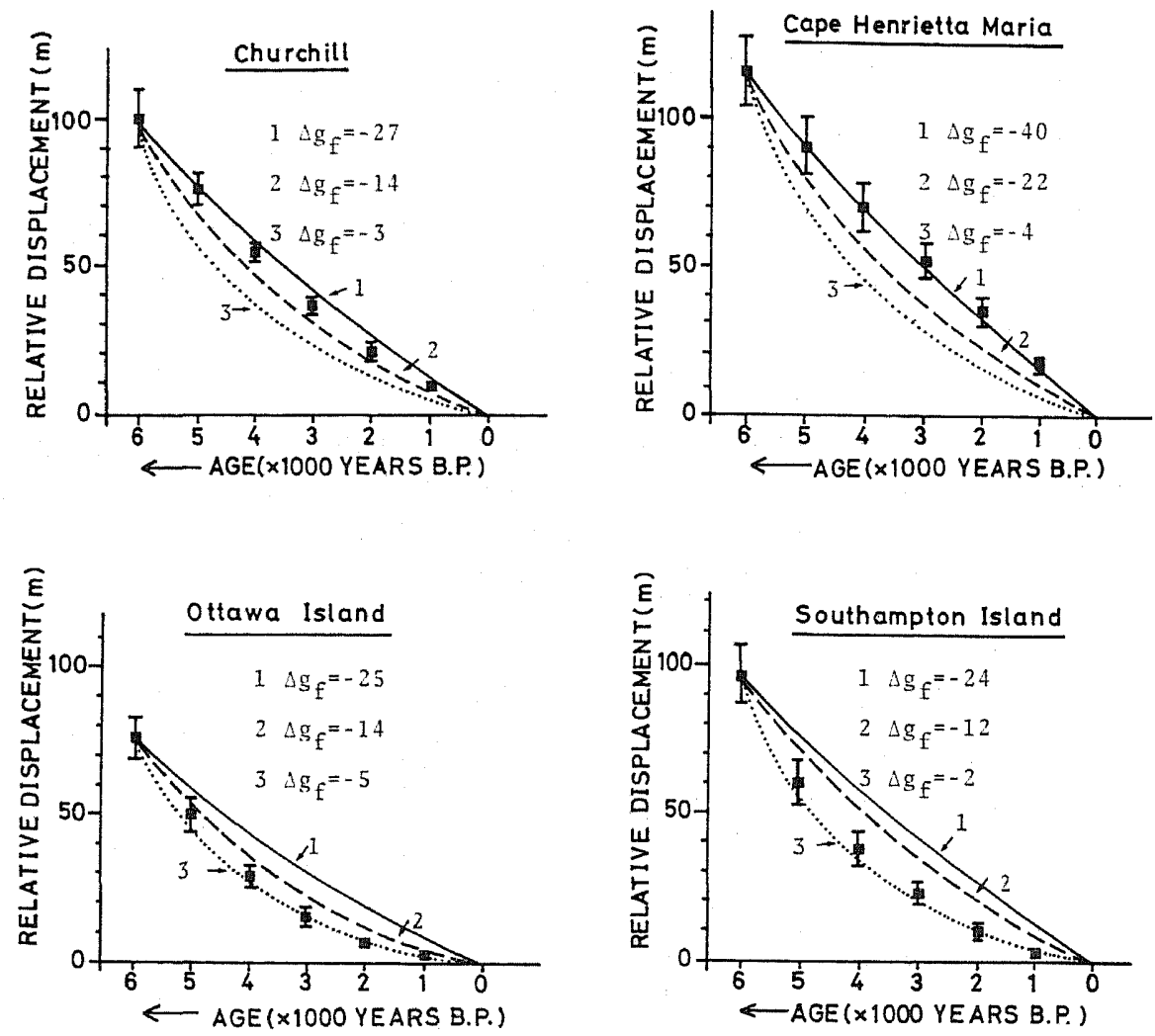

Fig. 4(a)

Fig. 4. Observed and theoretical relative sea levels. Observed relative sea levels are represented by solid square with error bar. The calculated free-air gravity anomalies based on each rheological model are shown in each figure. Observed free-air gravity anomalies at Churchill, Cape Henrietta Maria, Ottawa Island, and Southampton Island are about $-30,-30,-20$, and -20 mgal, respectively. In these calculations, flexural rigidity $F$ is assumed to be $1 \times 10^{32} \mathrm{dyn} \cdot \mathrm{cm}$. (a) Uniform viscosity models with viscosity $1 \times 10^{22}$ poise (short dashed line), $3 \times 10^{22}$ poise (long dashed line), and $5 \times 10^{22}$ poise (solid line). (b) Viscosity of lower part $\eta_{1}$ is $5 \times 10^{22}$ poise and the thickness of upper viscous layer $H$ is $200 \mathrm{~km}$. The viscosity of upper part $\eta_{\mathrm{a}}$ is shown in each figure. (c) Viscosity of lower part $\eta_{1}$ is $1 \times 10^{24}$ poise and the thickness of upper viscous layer $H$ is $200 \mathrm{~km}$. The viscosity of upper part $\eta_{\mathrm{a}}$ is shown in each figure. (d) Viscosity of lower part $\eta_{1}$ is $1 \times 10^{25}$ poise and the thickness of upper viscous layer $H$ is $200 \mathrm{~km}$. The viscosity of upper part $\eta_{\mathrm{a}}$ is shown in each figure. 

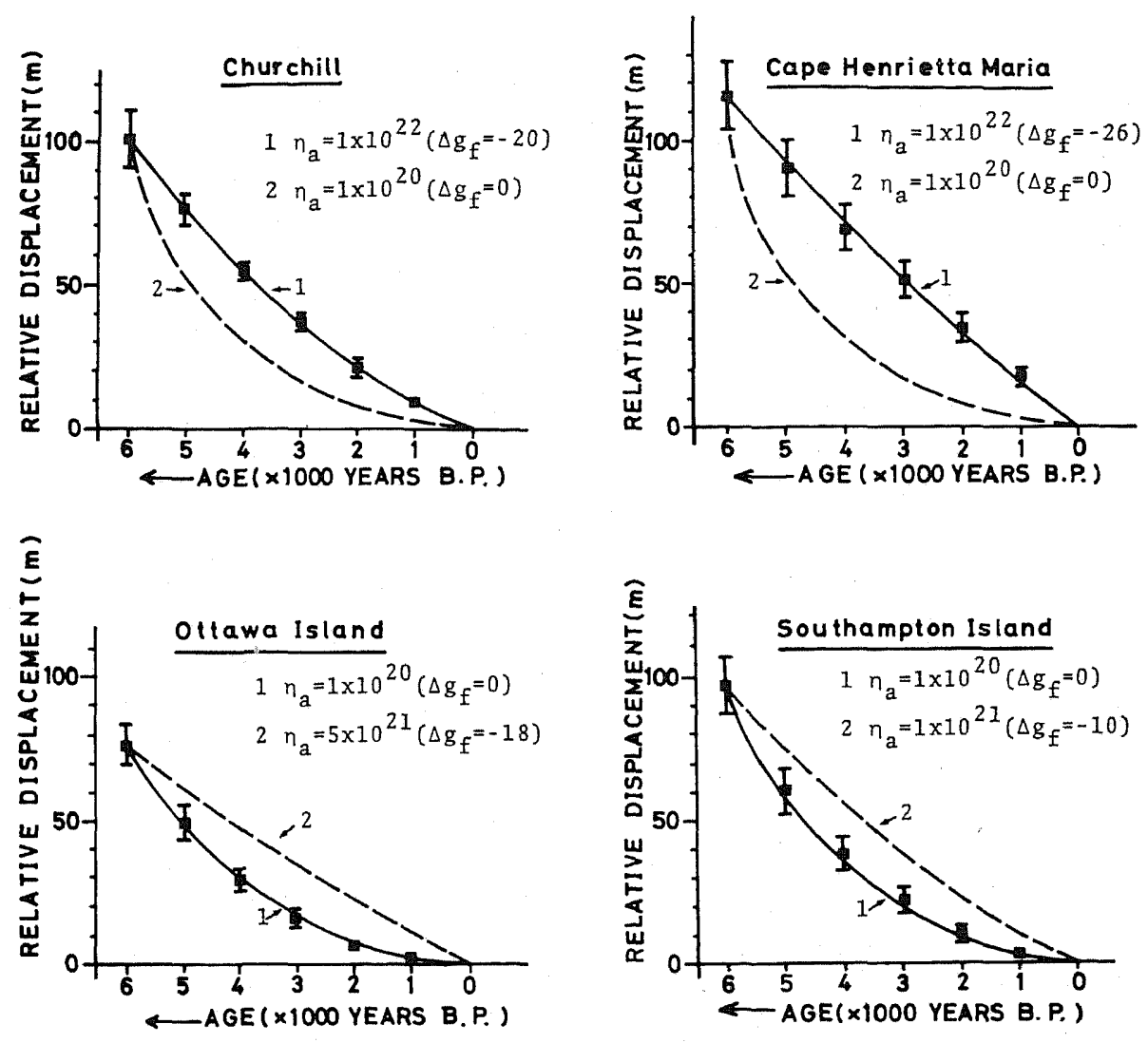

Fig. 4(b)

$\Delta \zeta(x, y, 2,000)$ using (2.9), and gravity anomalies with use of (2.6). The calculation results were compared with the observations. We chose as $t_{\mathrm{p}} 6,000$ years B.P., because eustatic sea level has been stable since 6,000 years B.P. according to Walcott (1972b, 1973, 1980) and Paterson (1972).

For the comparison between theoretical and observed sea levels, we selected data locations that seem to well represent the nature of sea level change over the entire region of Laurentide. Churchill and Cape Henrietta Maria (see Fig. 3) are situated near the center of the postglacial rebound. Ottawa Island and Southampton Island are also located in the glaciated region but at some distance from the center. Brigantine is located in the forebulge region. The relative sea level curves calculated by PeLtIER et al. (1978) and CLARK et al. (1978) show significant misfit with the observed data at all these locations. Nevertheless, we do not neglect the disagreement because the displacements at these locations are largest in the deformation related to glacial rebound, and these data should provide important constraints on the viscosity model of the earth's mantle. 

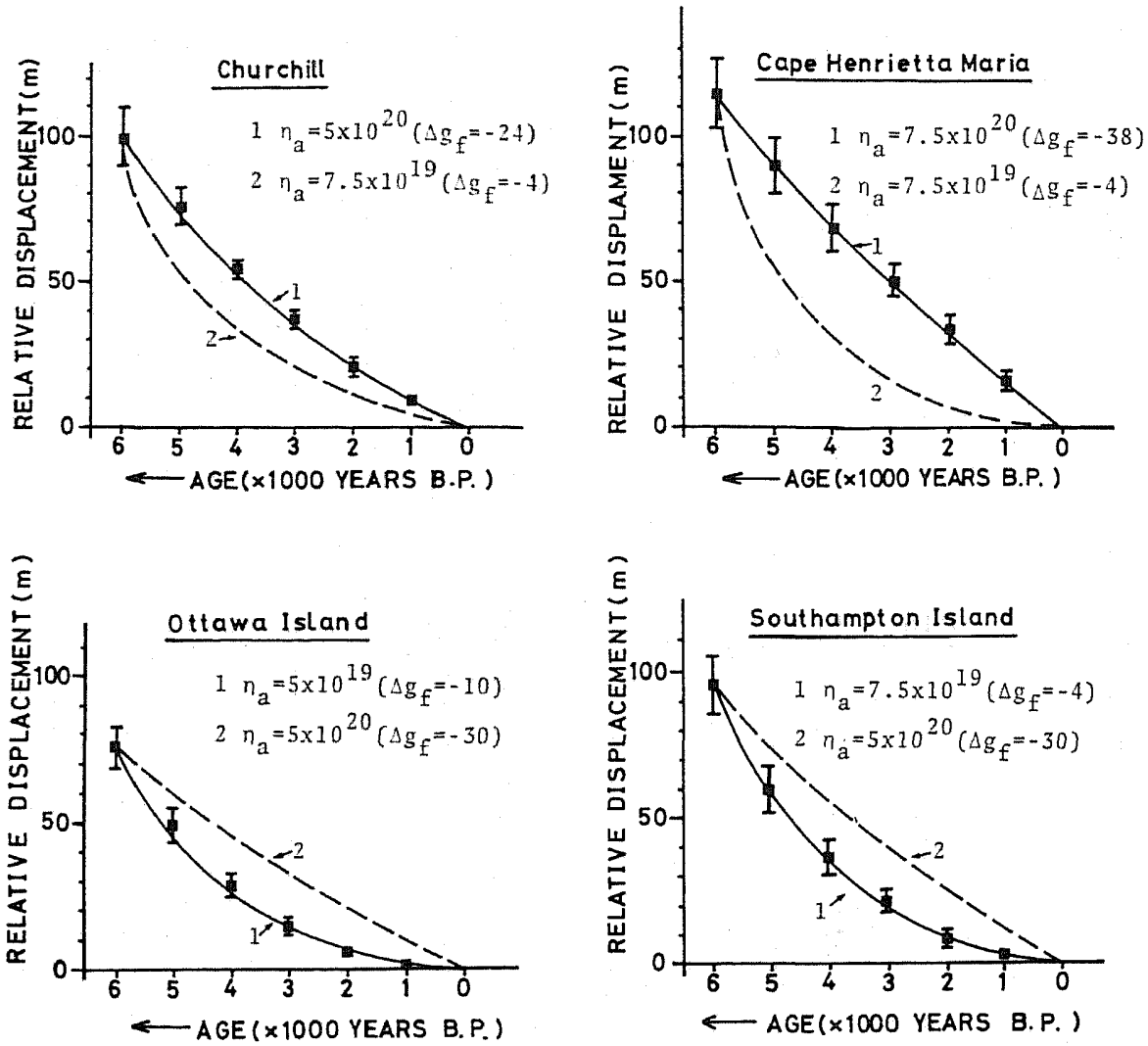

Fig. 4(c)

The calculated relative sea level curves for some viscosity structures of the earth's mantle are shown with observed data in the glaciated region in Fig. 4 and near the forebulge region (at Brigantine) in Fig. 5. Table 1 shows the fitted viscosity structures of the earth's mantle with the lower mantle viscosity of $5 \times 10^{22}$, $1 \times 10^{24}$, and $1 \times 10^{25}$ poise that explain the observed relative sea level data at each location. The calculated free-air gravity anomalies at each location based on each model are also shown in this table. In these calculations, we adopted as flexural rigidity $1 \times 10^{32} \mathrm{dyn} \cdot \mathrm{cm}$, which probably gives an upper limit of various estimates (WALCOTT, 1970b). Even if the adopted flexural rigidity is less than $1 \times 10^{32} \mathrm{dyn} \cdot \mathrm{cm}$, the results of relative displacement and present remaining uplift are not significantly affected.

\subsection{Implications of the present results}

\subsubsection{Relative sea level}

As has been shown in Sec. 2.2, one viscosity model can be fitted to some part of the observed relative sea level curves (Fig. 4, Fig. 5, Table 1), but another model 

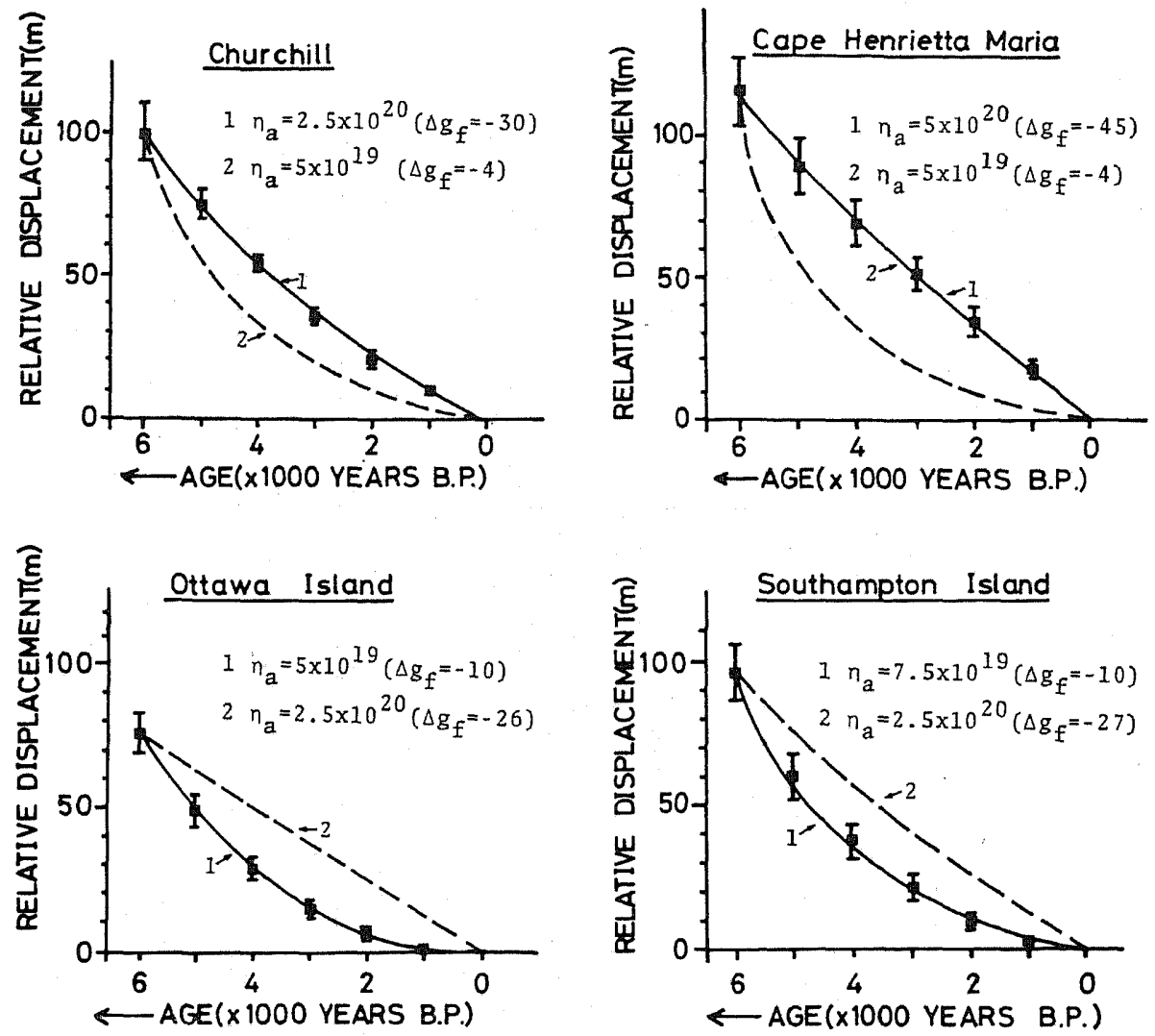

Fig. 4(d)

is required to fit other parts of the data. No viscosity model exists to explain all five observed relative sea level curves simultaneously. The apparent viscosity estimated from the fitting of the data at Churchill, Cape Henrietta Maria, and Brigantine is larger than those at Ottawa Island and Southampton Island. In other words, an apparent viscosity or relaxation time has spatial dependence over Laurentide. The apparent viscosity to explain the relative sea level pattern in the central part of Laurentide is approximately ten times larger than those in the surrounding area. The apparent upper mantle viscosity $\eta_{\mathrm{a}}$ at each location, with the lower mantle viscosity of $1 \times 10^{24}$ poise and $H=200 \mathrm{~km}$, that explains the observed relative sea level change at each location is shown in Fig. 6. The abovementioned spatial dependence of apparent viscosity is clearly recognized in this figure.

It is necessary to find a rheological model to explain the spatial dependence of apparent viscosity at least in the glaciated region. The relative sea level in the glaciated region should give most important constraint on the viscosity model of the earth's mantle. 


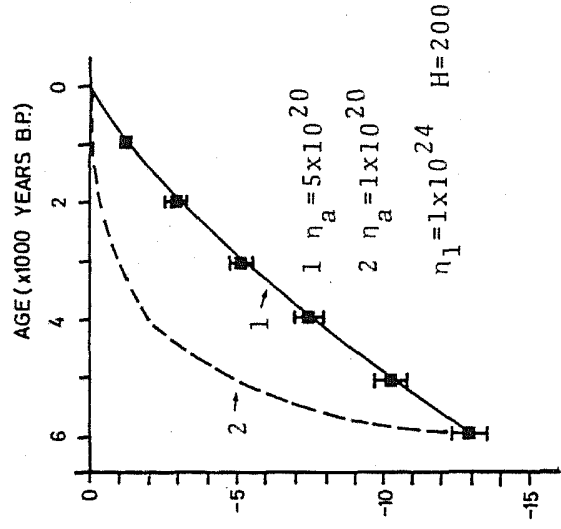

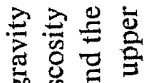

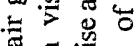

离 हี

을 क्षे

(2)

可至

的

हु플

$\dot{\theta}$ 范

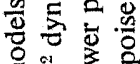

웅 응

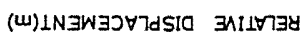

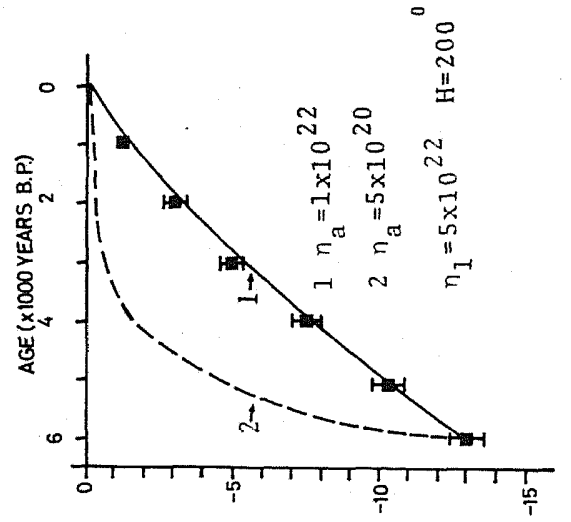

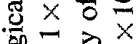

응 홍

迸

实官

穿.

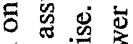

总. 음

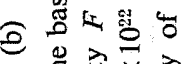

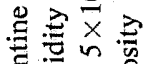

总记

ब西 $>$

苛产

एक

(แ) INजN

迥

0 皮

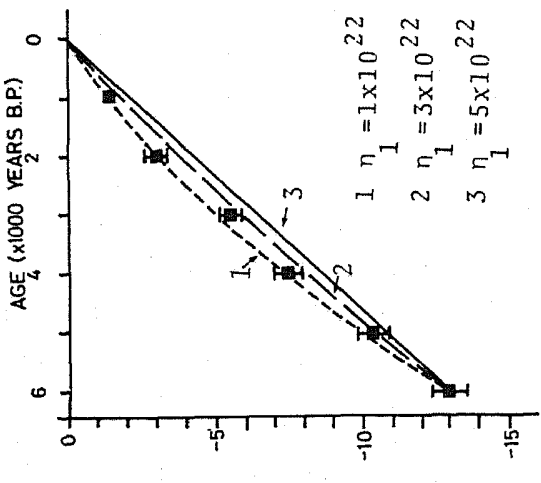

$\overrightarrow{0}$.

可完

띃

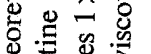

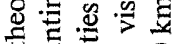

․ㅗㄹ

๔ ฮิ

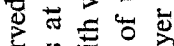

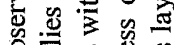

○े 증

的芯导兽

完

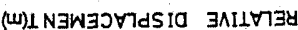



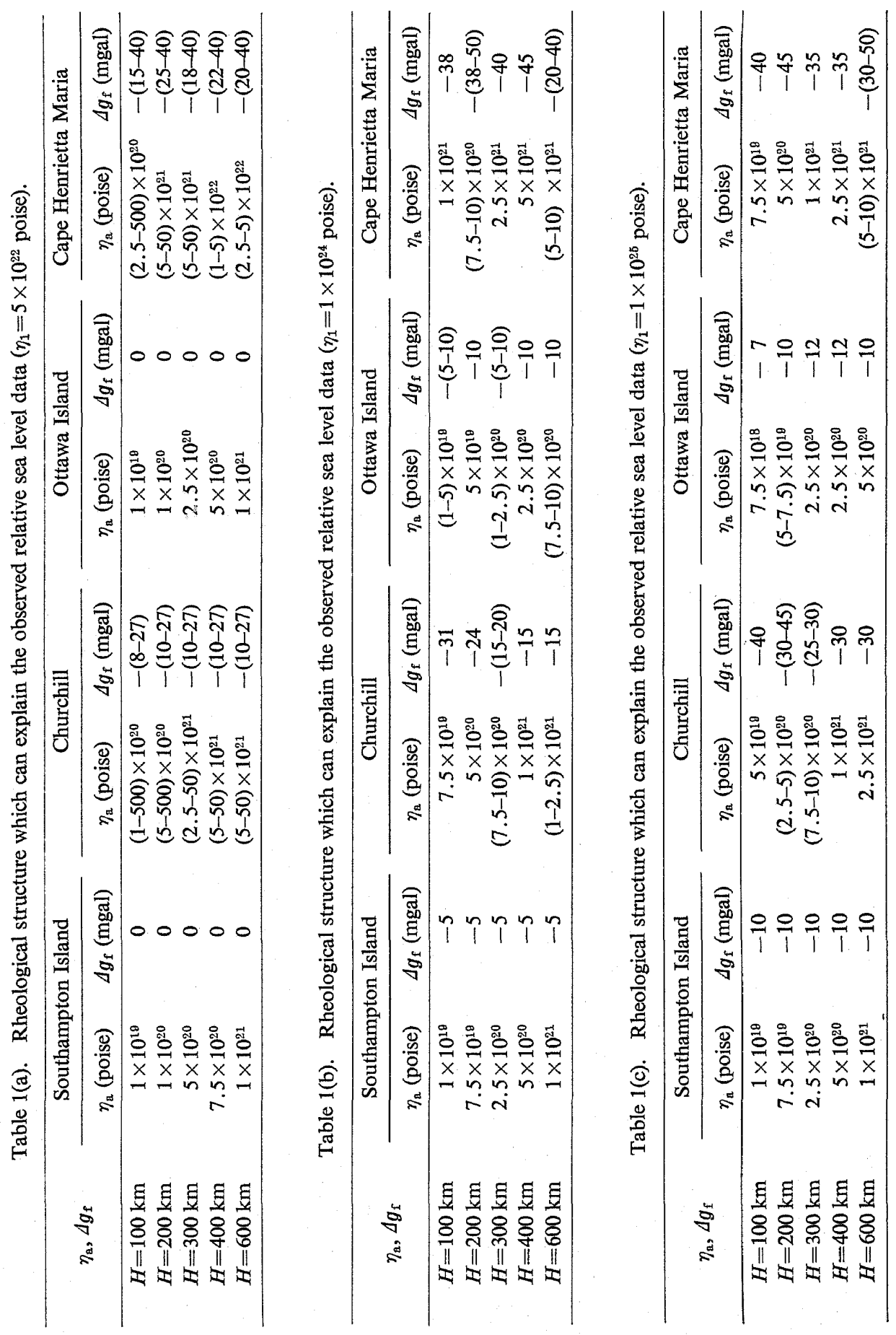


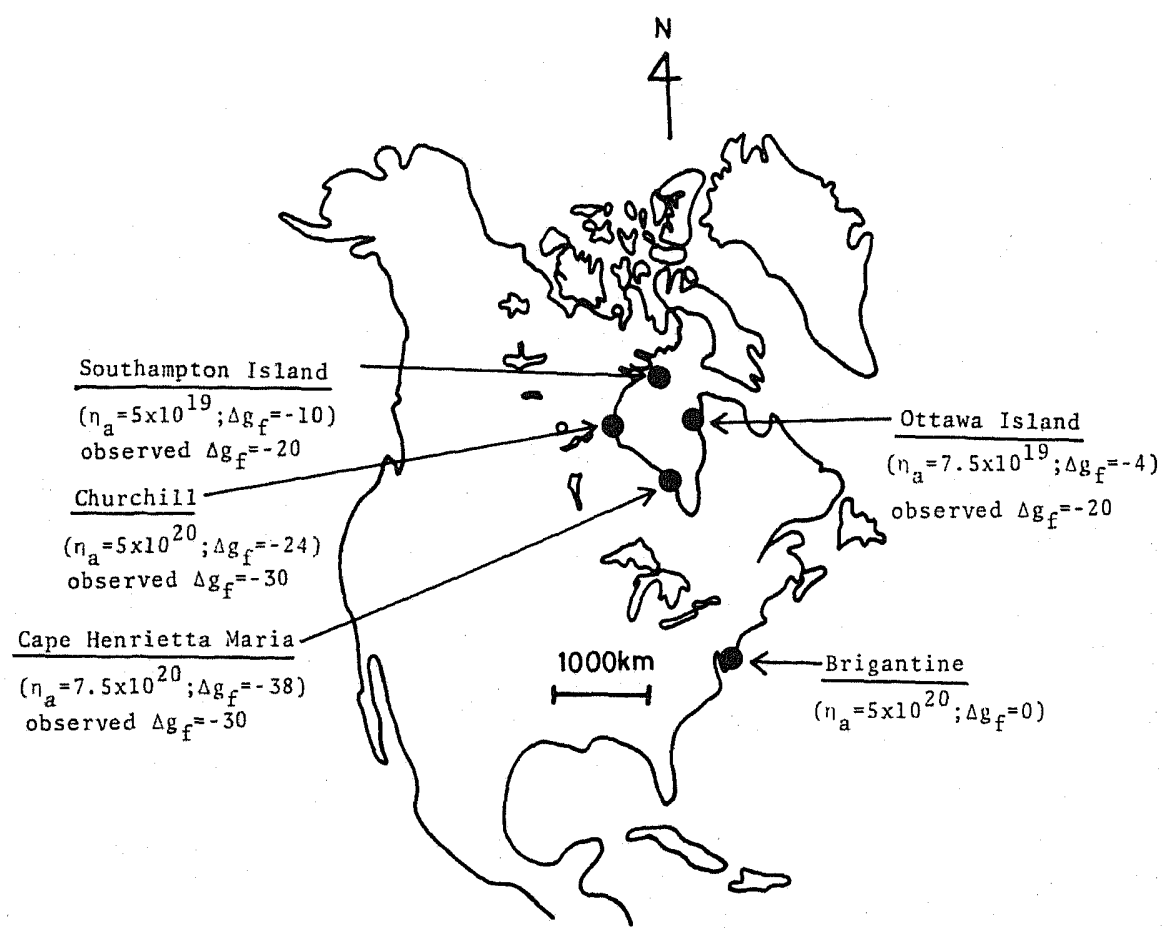

Fig. 6. Apparent viscosity with lower part viscosity $\eta_{1} 1 \times 10^{24}$ poise and the thickness of upper viscous layer is $200 \mathrm{~km}$. This figure shows that apparent viscosity at Churchill, Cape Henrietta Maria, and Brigantine is larger than that at Ottawa Island and Southampton Island.

\subsubsection{Free-air gravity anomalies}

The free-air gravity anomaly pattern compiled by WALCoTT (1970a) is well correlated with the relative sea level pattern in the glaciated region. Although CATHLES (1975) regarded this similarity as being accidental, it would be more natural to understand that these free-air gravity anomalies mainly correspond to the present remaining uplift that has not yet relaxed. As was indicated by WALCOTT (1972b, 1973), it is not certain that the observed negative free-air gravity anomalies in the glaciated area correspond perfectly to the remaining uplift. However, considering the good correlation between the shape of the glaciated area and the zone of the observed negative free-air gravity, and Kaula's indication that negative free-air anomalies do appear to be commonly associated with areas of rebound (KAULA, 1972), WALCOTT (1972b, 1973) suggested that most of the observed negative free-air gravity anomalies in Laurentide correspond to the present remaining uplift that has not yet relaxed and $300 \pm 120 \mathrm{~m}$ of vertical movement remain. $300 \pm 120 \mathrm{~m}$ of remaining uplift correspond to the negative freeair gravity anomalies of $-40 \pm 16 \mathrm{mgal}$.

Figure 4 and Table 1 show the theoretical free-air gravity anomalies based 
on the laterally homogeneous viscosity models of a Newtonian rheology. If the lower mantle viscosity is as small as $1 \times 10^{22}$ poise, free-air gravity anomalies should almost vanish over the Laurentide area, as was shown by CATHLES (1975). The observed free-air gravity anomalies read from the map compiled by WALCOTT (1970a) at Churchill, Cape Henrietta Maria, Southampton Island, and Ottawa Island are about $-30,-30,-20$, and $-20 \mathrm{mgal}$, respectively. The free-air gravity anomalies corresponding to the remaining uplift will have a difference of about $\pm 10 \mathrm{mgal}$ for these observed free-air gravity anomalies. Observed freeair gravity anomaly can be explained by the uniform viscosity of $5 \times 10^{22}$ poise throughout the mantle. Alternatively, the same gravity anomaly may be attributed to a thin channel viscosity model with the lower mantle viscosity of $1 \times 10^{24}$ poise, as has been shown for Cape Henrietta Maria and Churchill in Fig. 4 and Table 1.

In this paper, we do not discuss the free-air gravity anomalies at Brigantine located in the forebulge region. Free-air gravity pattern in the forebulge region, which is located on about the boundary between ocean and continent, is very complex (WALCOTT, 1970a), and it may be impossible to define the free-air gravity anomalies connected with the isostatic adjustment in Laurentide. The calculated free-air gravity anomalies based on the models shown in Fig. 5 are within 0 to a few mgal.

\subsubsection{The relation between vertical displacement and velocity}

The relation between displacement $\zeta$ and velocity $\zeta$ is often used in the discussion of mantle rheology. Figure 7 gives examples of the relation for the central parts of Laurentide and Fennoscandia (WALCOTT, 1972b; LliboutRY, 1971). The present displacement is estimated from the observed free-air gravity anomaly. The data are well fitted to the relation $\dot{\zeta} \propto \zeta^{m}$. The power $m$ in this expression was estimated to be about 3 for both Laurentide and Fennoscandia by YokokURA and SAITO (1978) and LliBouTRY (1971). Even if we consider the uncertainty of the present remaining uplift estimated from the gravity data, the power of $m$ is not so different and about 3 (YoKoKURA, 1978).

Post and GRIGgs (1973) and YoKoKURA and SAITo (1978) attributed the nonlinearity of the relation between $\dot{\zeta}$ and $\zeta$ to the nonlinear constitutive relation of mantle rheology $\dot{\varepsilon} \propto \sigma^{m}$ between strain rate $\dot{\varepsilon}$ and the deviatoric stress $\sigma$. However the validity of such interpretation is questionable. PosT and GrigGs (1973) assumed that the deformation associated with the uplift is kept self-similar with time. Unfortunately, this assumption of self-similarity does not hold because the depression gradually expands outwards, being smoothed out, as it decays (WALCOTt, 1980). Lliboutry (1971) showed that the nonlinear relation between $\dot{\zeta}$ and $\zeta$ can be explained by a Newtonian viscosity in a thin channel model, if the initial distribution of $\zeta$ is gaussian. Therefore the power law creep in the mantle cannot be concluded from the observed nonlinear relation $\dot{\zeta} \propto \zeta^{3-4}$.

Figure 8 shows the relation between $\zeta$ and $\zeta$ at Cape Henrietta Maria that was calculated for Newtonian rheology in the framework of the present treat- 


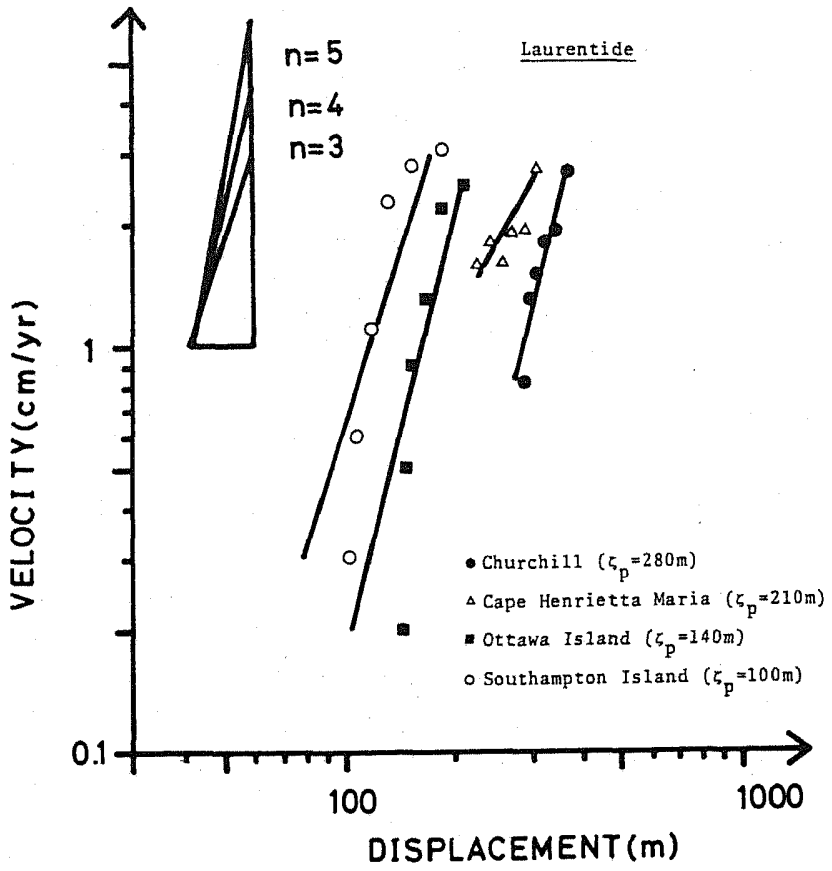

(a)

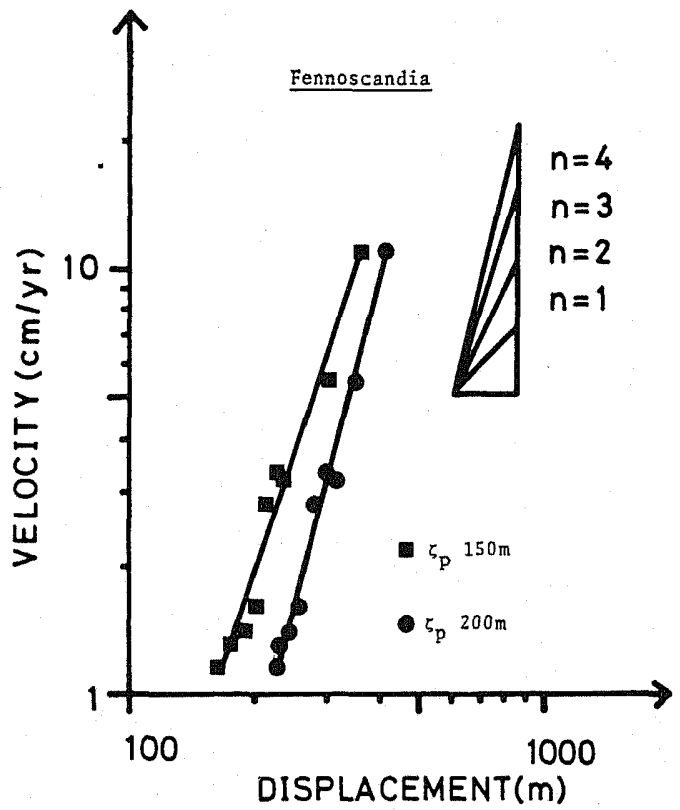

(b)

Fig. 7. The relation between observed uplift rate $\dot{\zeta}$ (velocity) and remaining uplift $\zeta$. The remaining uplift at each location is estimated by free-air gravity anomalies. (a) Laurentide, (b) Fennoscandia. 


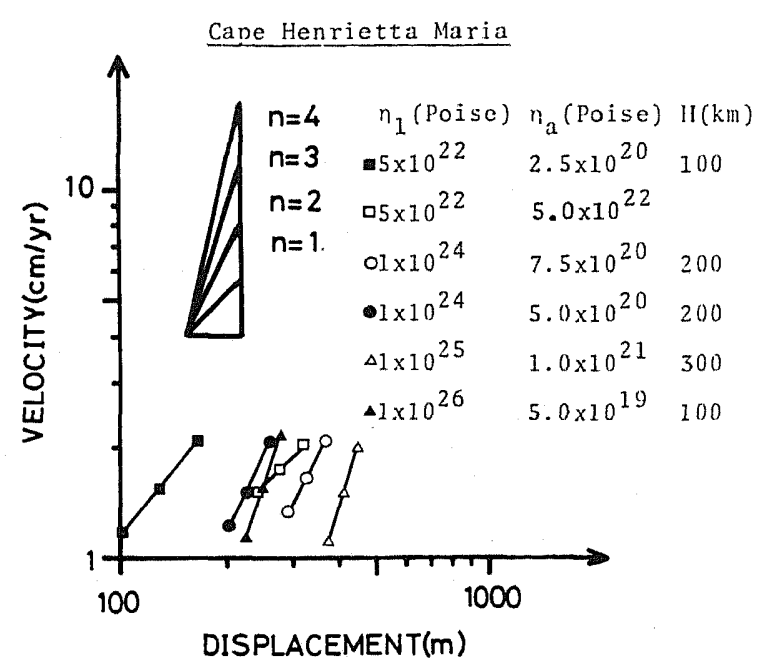

Fig. 8. The relation between calculated uplift rate and remaining uplift at Cape Henrietta Maria. The rheological models are shown in this figure. Flexural rigidity $F$ is assumed to be $1 \times 10^{32} \mathrm{dyn} \cdot \mathrm{cm}$.

ment. In this calculation, displacement $\zeta$ was obtained from relative sea level data alone without using the observed free-air gravity anomalies. The power $m$ is almost unity for the uniform viscosity model with the lower mantle viscosity $5 \times 10^{22}$ poise. The value of $m$ becomes 2 to 3 if the lower mantle viscosity is increased to $1 \times 10^{24}$ poise. The value of $m$ approaches 3 for more than $1 \times 10^{25}$ poise of the lower mantle viscosity. This result, as well as the work by LLIBOUTRY (1971), suggests that the observed nonlinear relation between displacement and velocity supports a thin channel viscosity model rather than power-law creep law. Namely the observed relation of $\dot{\zeta} \propto \zeta^{3-4}$ in Laurentide and Fennoscandia points out that the lower mantle has such high viscosity that a thin channel model may be applicable rather than a uniform viscosity model.

\section{Analysis Based on a Power-Law Creep Rheology}

3.1 Nonlinear equation based on the thin channel viscosity model of a powerlaw creep rheology

Figure 9 shows the model with a thin low viscosity channel employed in this section. We assume that representative horizontal scale $L$ of the surface disturbance is sufficiently greater than the thickness $H$ of the fluid layer participating in the relaxation process, i.e., $L \gg H$. Under this assumption, we may assume $\partial \Phi / \partial z \gg \partial \Phi / \partial x, \partial \Phi / \partial y$ for an arbitrary function $\Phi=\Phi(x, y, z, t)$. Let us denote velocity, gravitational acceleration, displacement, and density by $V=(u, v, w)$, $\boldsymbol{g}=(0,0,-g), \zeta$ and $\rho$, respectively. Velocity $\boldsymbol{V}$ is a function of position $\boldsymbol{X}=$ $(x, y, z)$ and time $t$. Coordinate $z$ is taken positive upward. Displacement $\zeta$ on 


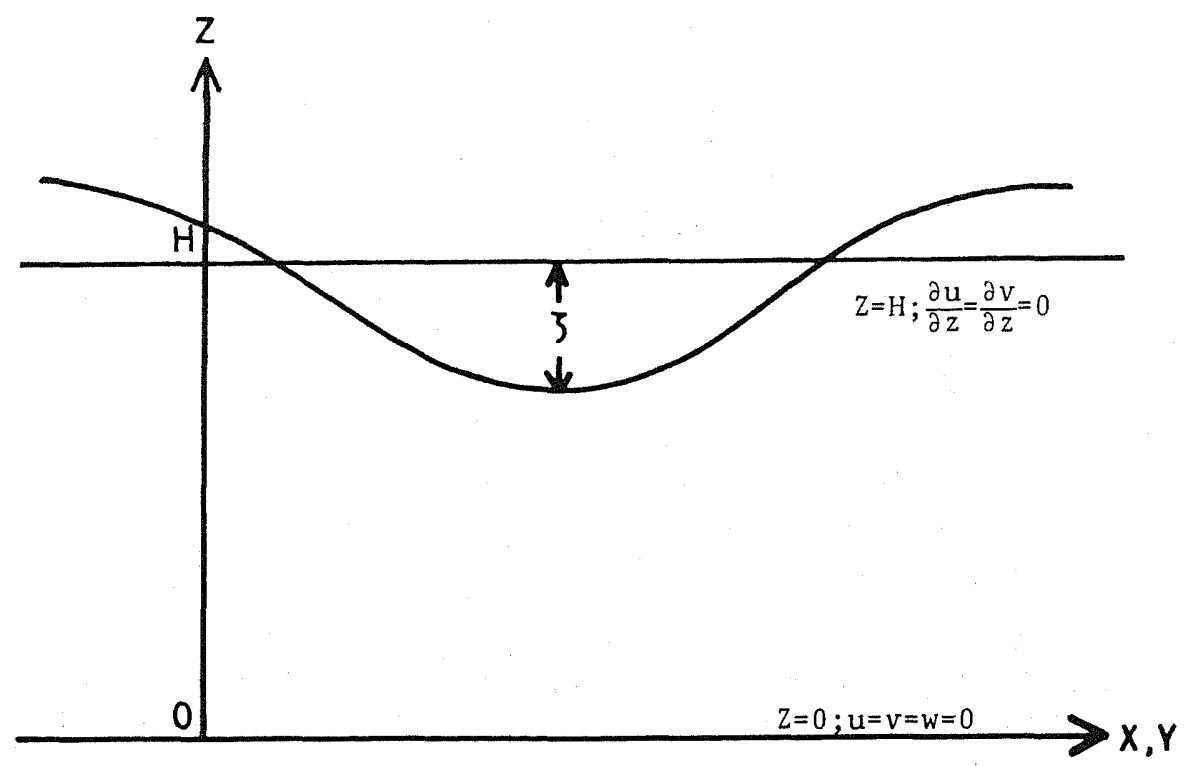

Fig. 9. Rheological model and boundary conditions used for analysis based on a power-law creep rheology.

the surface is a function of $x, y$, and $t$. Gravitational acceleration and density are assumed to be independent of space and time.

The boundary conditions may be prescribed as

$$
u=v=w=0 \quad \text { at } \quad z=0
$$

at the bottom of the fluid layer, and

$$
\frac{\partial u}{\partial z}=\frac{\partial v}{\partial z}=0 \quad \text { at } \quad z=H
$$

at the surface of the fluid. The constitutive relation between $\sigma_{i j}{ }^{\prime}$ and $\dot{\varepsilon}_{i j}$ for powerlaw creep is expressed as

$$
\dot{\varepsilon}_{i j}=A J_{\sigma}^{(n-1) / 2} \sigma_{i j}^{\prime},
$$

where $\sigma_{i j}^{\prime}$ and $\dot{\varepsilon}_{i j}$ respectively represent deviatoric stress and strain rate tensor. The pre-exponential factor $A$ mainly depends on temperature, and thus we may allow $A$ to change as a function of depth $z$. Equation (3.2) with $n=1$ gives a Newtonian fluid. In (3.2), $J_{\sigma}$ is the second invariant of deviatoric stress tensor and defined by

$$
J_{\sigma}=\frac{1}{2} \sigma_{i j}{ }^{\prime} \sigma_{i j^{\prime}}
$$

The equation of motion is 


$$
\begin{gathered}
-\frac{\partial p}{\partial x}+\frac{\partial \sigma_{x x}^{\prime}}{\partial x}+\frac{\partial \sigma_{x y}{ }^{\prime}}{\partial y}+\frac{\partial \sigma_{x z}^{\prime}}{\partial z}=0 \\
-\frac{\partial p}{\partial y}+\frac{\partial \sigma_{x y}^{\prime}}{\partial x}+\frac{\partial \sigma_{y y}^{\prime}}{\partial y}+\frac{\partial \sigma_{y z}^{\prime}}{\partial z}=0 \\
-\frac{\partial p}{\partial z}+\frac{\partial \sigma_{x z}^{\prime}}{\partial x}+\frac{\partial \sigma_{y z}^{\prime}}{\partial y}+\frac{\partial \sigma_{z z}^{\prime}}{\partial z}-\rho g=0
\end{gathered}
$$

where the inertia terms are neglected as usual. The equation of continuity is

$$
\frac{\partial u}{\partial x}+\frac{\partial v}{\partial y}+\frac{\partial w}{\partial z}=0 \text {. }
$$

We introduce the second invariant of strain rate tensor $J_{\varepsilon}$ :

$$
J_{\varepsilon}=\frac{1}{2} \dot{\varepsilon}_{i j} \dot{\varepsilon}_{i j}
$$

Using (3.3) and (3.8), we have the following relation between $J_{\sigma}$ and $J_{\varepsilon}$ :

$$
J_{\sigma}^{n}=A^{-2} J_{\varepsilon} \text {. }
$$

Effective viscosity is defined in the following:

$$
\nu=\frac{\sigma_{i j}^{\prime}}{2 \dot{\varepsilon}_{i j}} .
$$

Using (3.2) and (3.9), effective viscosity $\nu$ is expressed as

$$
\nu=\frac{1}{2} A^{-(1 / n)} J_{\varepsilon}^{(1-n) / 2 n} .
$$

Considering the assumption of $L \gg H, J_{\varepsilon}$ is expressed as

$$
J_{\varepsilon}=\frac{1}{4}\left[\left(\frac{\partial u}{\partial z}\right)^{2}+\left(\frac{\partial v}{\partial z}\right)^{2}\right] \text {. }
$$

Putting (3.12) into (3.11), effective viscosity is expressed as

$$
\nu=C_{n}\left[\left(\frac{\partial u}{\partial z}\right)^{2}+\left(\frac{\partial v}{\partial z}\right)^{2}\right]^{(1-n) / 2 n},
$$

where $C=(2 A)^{-1 / n}$. Applying the assumption of $L \gg H$ on (3.4), (3.5), and (3.6), and using (3.13), equation of motion is reduced to

$$
\begin{gathered}
-\frac{\partial p}{\partial x}+\frac{\partial}{\partial z}\left(\nu \frac{\partial u}{\partial z}\right)=0 \\
-\frac{\partial p}{\partial y}+\frac{\partial}{\partial z}\left(\nu \frac{\partial v}{\partial z}\right)=0 \\
-\frac{\partial p}{\partial z}-\rho g=0
\end{gathered}
$$

Integrating (3.4) with respect to $z$, we have 


$$
p=-\rho g(H-z)+\rho g \zeta+R,
$$

where $R$ is the pressure owing to the surface load, and a function of position $(x, y)$ and time $t$. Putting (3.13) and (3.17) into (3.14) and (3.15), we find

$$
\begin{aligned}
& \frac{\partial}{\partial z}\left(C_{n} \Gamma^{(1-n) / 2 n} \frac{\partial u}{\partial z}\right)=\rho g \frac{\partial \tilde{\zeta}}{\partial x} \\
& \frac{\partial}{\partial z}\left(C_{n} \Gamma^{(1-n) / 2 n} \frac{\partial v}{\partial z}\right)=\rho g \frac{\partial \tilde{\zeta}}{\partial y},
\end{aligned}
$$

where $\tilde{\zeta}$ and $\Gamma$ are defined by

$$
\begin{gathered}
\tilde{\zeta}=\zeta+\frac{R}{\rho g} \\
\Gamma=\left(\frac{\partial u}{\partial z}\right)^{2}+\left(\frac{\partial v}{\partial z}\right)^{2} .
\end{gathered}
$$

We further operate $\int_{H}^{z} \mathrm{~d} z$ on (3.18) and (3.19). Applying (3.1.2) to the resultant equation, we have

$$
\begin{aligned}
& C_{n} \Gamma^{(1-n) / 2 n} \frac{\partial u}{\partial z}=\rho g(z-H) \frac{\partial \tilde{\zeta}}{\partial x} \\
& C_{n} \Gamma^{(1-n) / 2 n} \frac{\partial v}{\partial z}=\rho g(z-H) \frac{\partial \tilde{\zeta}}{\partial y} .
\end{aligned}
$$

We define the following value:

$$
r=-\rho g(z-H) / C_{n} \Gamma^{(1-n) / 2 n} .
$$

Since $C_{n}$ and $\Gamma$ are positive and $(z-H)$ is negative, $r$ is positive. Applying (3.24) on Eqs. (3.22) and (3.23), $\partial u / \partial z$ and $\partial v / \partial z$ are respectively expressed as

$$
\begin{aligned}
& \frac{\partial u}{\partial z}=-r \frac{\partial \tilde{\zeta}}{\partial x} \\
& \frac{\partial v}{\partial z}=-r \frac{\partial \tilde{\zeta}}{\partial y} .
\end{aligned}
$$

By using the relation $C_{n}=(2 A)^{-1 / n}$ and the definition of $\Gamma$, we have the following expression of $r$ :

$$
r=2 A[\rho g(H-z)]^{n} \Pi^{(n-1) / 2},
$$

where $\Pi$ is defined by

$$
\Pi=\left(\frac{\partial \tilde{\zeta}}{\partial x}\right)^{2}+\left(\frac{\partial \tilde{\zeta}}{\partial y}\right)^{2}
$$

Putting (3.27) into (3.25) and (3.26), we find

$$
\frac{\partial u}{\partial z}=-2 A[\rho g(H-z)]^{n} \Pi^{(n-1) / 2} \frac{\partial \tilde{\zeta}}{\partial x}
$$




$$
\frac{\partial v}{\partial z}=-2 A[\rho g(H-z)]^{n} \Pi^{(n-1) / 2} \frac{\partial \tilde{\zeta}}{\partial y}
$$

Operating $\int_{0}^{z} \mathrm{~d} z$ on (3.29) and (3.30), and using (3.1.1), we find

$$
\begin{aligned}
& u=-K(z) \Pi^{(n-1) / 2} \frac{\partial \tilde{\zeta}}{\partial x} \\
& v=-K(z) \Pi^{(n-1) / 2} \frac{\partial \tilde{\zeta}}{\partial y},
\end{aligned}
$$

where $K(z)$ is defined by

$$
K(z)=\int_{0}^{z} 2 A[\rho g(H-z)]^{n} \mathrm{~d} z
$$

Operating $\int_{0}^{H} \mathrm{~d} z$ on (3.31) and (3.32), we obtain

$$
\begin{aligned}
& \int_{0}^{H} u \mathrm{~d} z=-D \Pi^{(n-1) / 2} \frac{\partial \tilde{\zeta}}{\partial x} \\
& \int_{0}^{H} v \mathrm{~d} z=-D \Pi^{(n-1) / 2} \frac{\partial \tilde{\zeta}}{\partial y}
\end{aligned}
$$

where a constant $D$ is defined by

$$
D=\int_{0}^{H} K(z) \mathrm{d} z=\int_{0}^{H} \int_{0}^{z} 2 A[\rho g(H-h)]^{n} \mathrm{~d} h \mathrm{~d} z .
$$

Operating $\int_{0}^{H} \mathrm{~d} z$ on (3.7), we have

$$
\int_{0}^{H} \frac{\partial w}{\partial z} \mathrm{~d} z=-\frac{\partial}{\partial x} \int_{0}^{H} u \mathrm{~d} z-\frac{\partial}{\partial y} \int_{0}^{H} v \mathrm{~d} z
$$

Remembering (3.1.1), the left-hand side of (3.37) is reduced to

$$
\int_{0}^{H} \frac{\partial w}{\partial z} \mathrm{~d} z=w(H)-w(0)=w(H)
$$

where $w(H)$ can be expressed in terms of surface displacement $\zeta$, as

$$
w(H)=\frac{\partial \zeta}{\partial t} .
$$

Putting (3.34), (3.35), and (3.38) into (3.37), we find

$$
\frac{\partial \zeta}{\partial t}=D\left[\frac{\partial}{\partial x}\left(\Pi^{(n-1) / 2} \frac{\partial \tilde{\zeta}}{\partial x}\right)+\frac{\partial}{\partial y}\left(\Pi^{(n-1) / 2} \frac{\partial \tilde{\zeta}}{\partial y}\right)\right] .
$$

This is the desired equation that controls the postglacial isostatic adjustment in the thin channel model with power-law creep rheology.

When $A$ is independent of depth $z, D$ in (3.36) is reduced to 


$$
D=\frac{2 A H^{n+2}}{n+2}(\rho g)^{n}
$$

For the Newtonian fluid without surface load, we may put $n=1$ and $R=0$ into (3.39) and (3.40) to get

$$
\frac{\partial \zeta}{\partial t}=\frac{\rho g H^{3}}{3 \eta}\left(\frac{\partial^{2} \zeta}{\partial x^{2}}+\frac{\partial^{2} \zeta}{\partial y^{2}}\right)
$$

where $\eta$ is a constant equal to $1 / 2 A$. (3.41) is exactly the same equation as VAN Bemmelen and Berlage (1935), ArtyushKov (1967, 1971), and Lliboutry (1971) obtained and used to investigate the viscosity of the earth's mantle. For $n=3$, (3.39) is rewritten as

$$
\frac{\partial \zeta}{\partial t}=D\left[\frac{\partial}{\partial x}\left\{\left(\left(\frac{\partial \tilde{\zeta}}{\partial x}\right)^{2}+\left(\frac{\partial \tilde{\zeta}}{\partial y}\right)^{2}\right) \frac{\partial \tilde{\zeta}}{\partial x}\right\}+\frac{\partial}{\partial y}\left\{\left(\left(\frac{\partial \tilde{\zeta}}{\partial x}\right)^{2}+\left(\frac{\partial \tilde{\zeta}}{\partial y}\right)^{2}\right) \frac{\partial \tilde{\zeta}}{\partial y}\right\}\right] .
$$

Even if there exists an elastic lithosphere with flexural rigidity $F$ on the surface of the fluid layer, the above formulation is applied if we change the definition of $\tilde{\zeta}$ in $(3.20)$ to

$$
\tilde{\zeta}=\zeta+\frac{R}{\rho g}+\frac{F}{\rho g}\left(\frac{\partial^{4} \zeta}{\partial x^{4}}+2 \frac{\partial^{4} \zeta}{\partial x^{2} \partial y^{2}}+\frac{\partial^{4} \zeta}{\partial y^{4}}\right),
$$

as was shown by CATHLEs (1975) in case of a Newtonian fluid. But it is assured in our calculation that the elasticity of the elastic lithosphere has only negligible effect on the relative sea level variation and remaining uplift in Laurentide if the flexural rigidity is less than $1 \times 10^{32} \mathrm{dyn} \cdot \mathrm{cm}$. The same conclusion has been already drawn for a Newtonian rheology.

3.2 Comparison of the relaxation processes of a Newtonian rheology and power-law creep rheology

Putting (3.29) and (3.30) into (3.13), the expression for the effective viscosity is rewritten as

$$
\nu=\frac{[\rho g(H-z)]^{1-n}}{2 A}\left[\left(\frac{\partial \zeta}{\partial x}\right)^{2}+\left(\frac{\partial \zeta}{\partial y}\right)^{2}\right]^{(1-n) / 2}
$$

We may define an apparent viscosity $\tilde{\nu}_{n}$ by

$$
\tilde{\Sigma}_{n}=\frac{1}{H} \int_{0}^{H} \nu \mathrm{d} z
$$

(3.45) shows that the apparent viscosity is constant over the surface when $n=1$, and changes from point to point when $n=3$. In the latter case, the apparent viscosity is less, as the gradient of displacement is greater, because $\tilde{\nu}_{n}$ is proportional to $\left[(\partial \zeta / \partial x)^{2}+(\partial \zeta / \partial y)^{2}\right]^{-1}$. A schematic pattern of the apparent viscosity may be displayed as in Fig. 10, corresponding to a probable displacement distribution associated with postglacial rebound. This figure is intended to show qualitatively that the region with flatter displacement field should have larger 

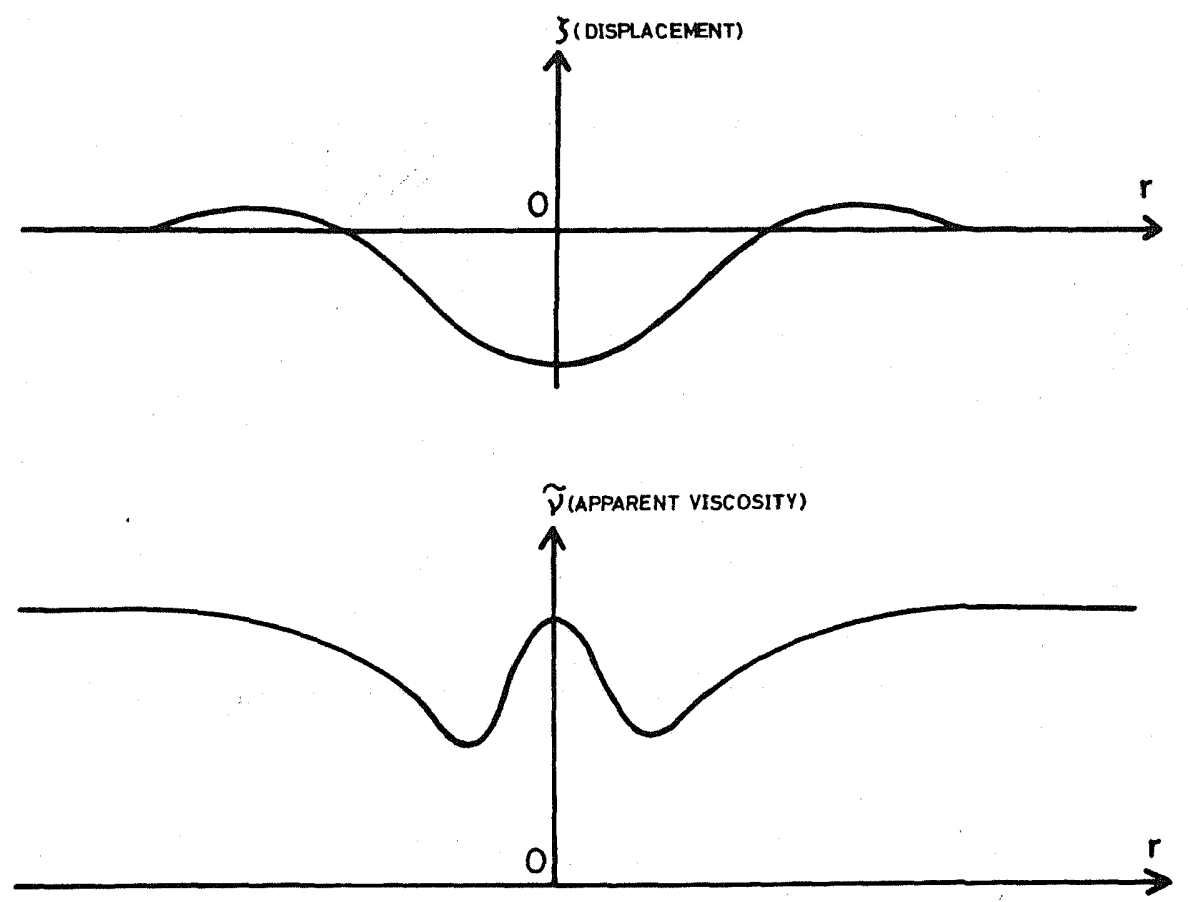

Fig. 10. Schematic distribution of apparent viscosity based on a power-law creep rheology $\left(\dot{\varepsilon} \propto \sigma^{3} ; n>1\right)$. The top figure shows a probable displacement distribution associated with postglacial rebound and the bottom figure shows the schematic apparent viscosity profile.

apparent viscosity than the region with steeper slope.

In this section, we consider the one-dimensional solutions (3.41) and (3.42), assuming that the solution does not depend on $y$. It has been found that Eq. (3.42) has an analytical solution (Appendix). Unfortunately, these analytical solutions do not satisfy both the boundary and initial conditions appropriate to the postglacial isostatic adjustment. Therefore we study the nature of solution by numerical calculation, solving each of the following equations numerically:

$$
\frac{\partial \zeta}{\partial t}=\frac{\partial^{2} \zeta}{\partial x^{2}}
$$

for Newtonian viscosity, and

$$
\frac{\partial \zeta}{\partial t}=\frac{\partial}{\partial x}\left[\left(\frac{\partial \zeta}{\partial x}\right)^{2} \frac{\partial \zeta}{\partial x}\right]
$$

for power-law creep of $n=3$. Both equations are for the laterally homogeneous thin channel viscosity model. Figure 11 compares the relaxation pattern between the solution of Eqs. (3.46) and (3.47). The initial condition is commonly given by an elliptic displacement of $\zeta$. This figure demonstrates that a steep gradient in the surface displacement is relaxed more quickly in the initial stage of the 

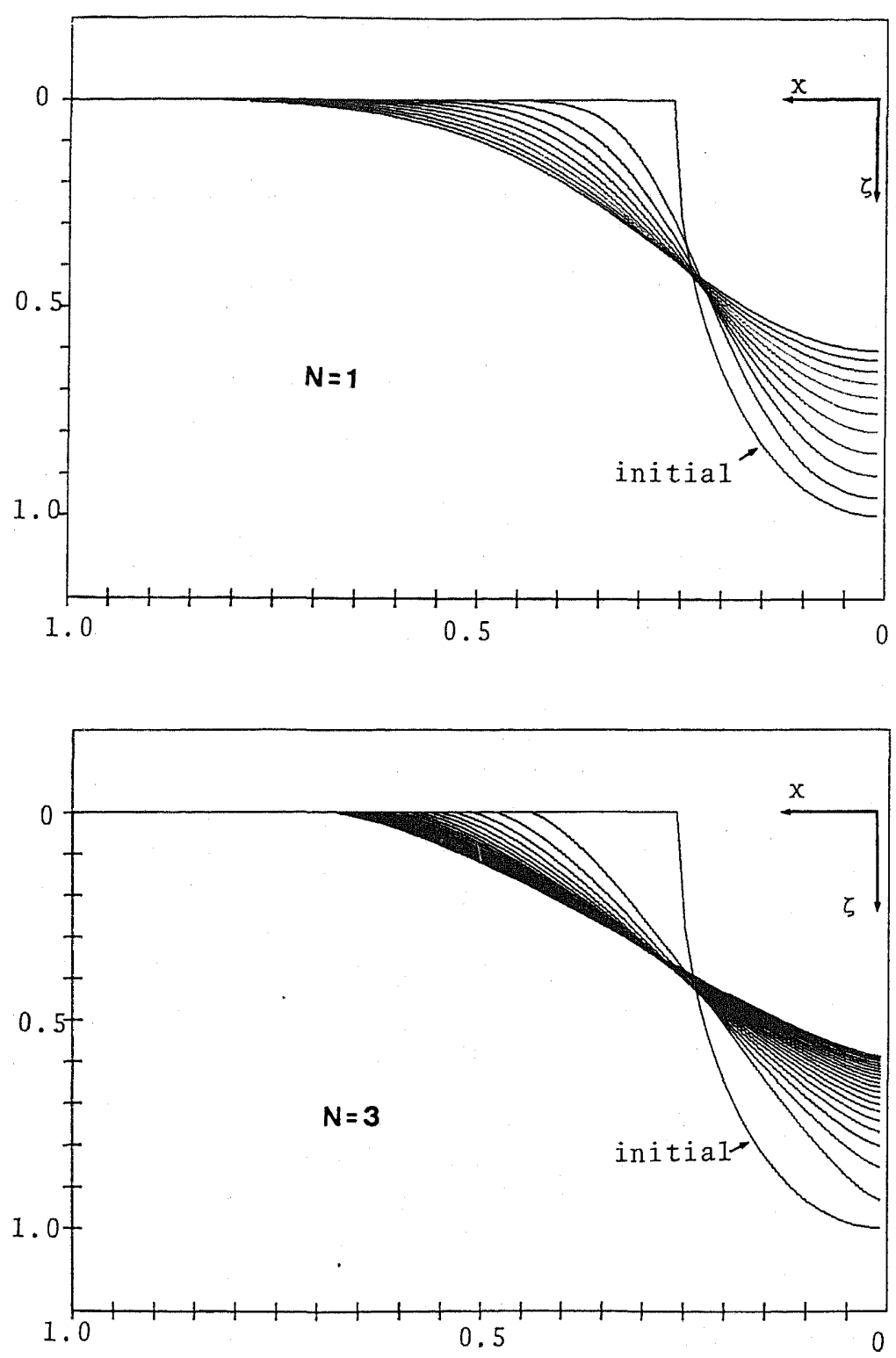

Fig. 11. Relaxation patterns based on Newtonian rheology $(n=1)$ and power-law creep theology $\dot{\varepsilon} \propto \sigma^{3}(n=3)$.

relaxation process in the power-law creep than in the Newtonian rheology. After the gradient of the displacement becomes almost constant all over the surface, the relaxation in the power-law creep occurs almost uniformly at each point. In the case of Newtonian rheology, the relaxation occurs almost uniformly at any time and any point (Fig. 11). 
The above-mentioned characteristic for the power-law creep is interpreted in terms of the spatial distribution of the apparent viscosity. The location with sharp gradient of displacement has lower viscosity and thus the deformation is relaxed there faster. Once the spatial gradient of the surface displacement is smoothed out in the initial stage, the relaxation process is qualitatively the same as in the case of Newtonian rheology, because the apparent viscosity is no longer non-uniform. Therefore, the effect of nonlinear creep law should be dominant in the initial stage where there is a significant variation in the gradient of the displacement from point to point.

3.3 Two-dimensional numerical solution based on a power-law creep rheology with $n=3$ and comparison with observed data

Figure 12 shows the deglaciation history employed in our calculation. The

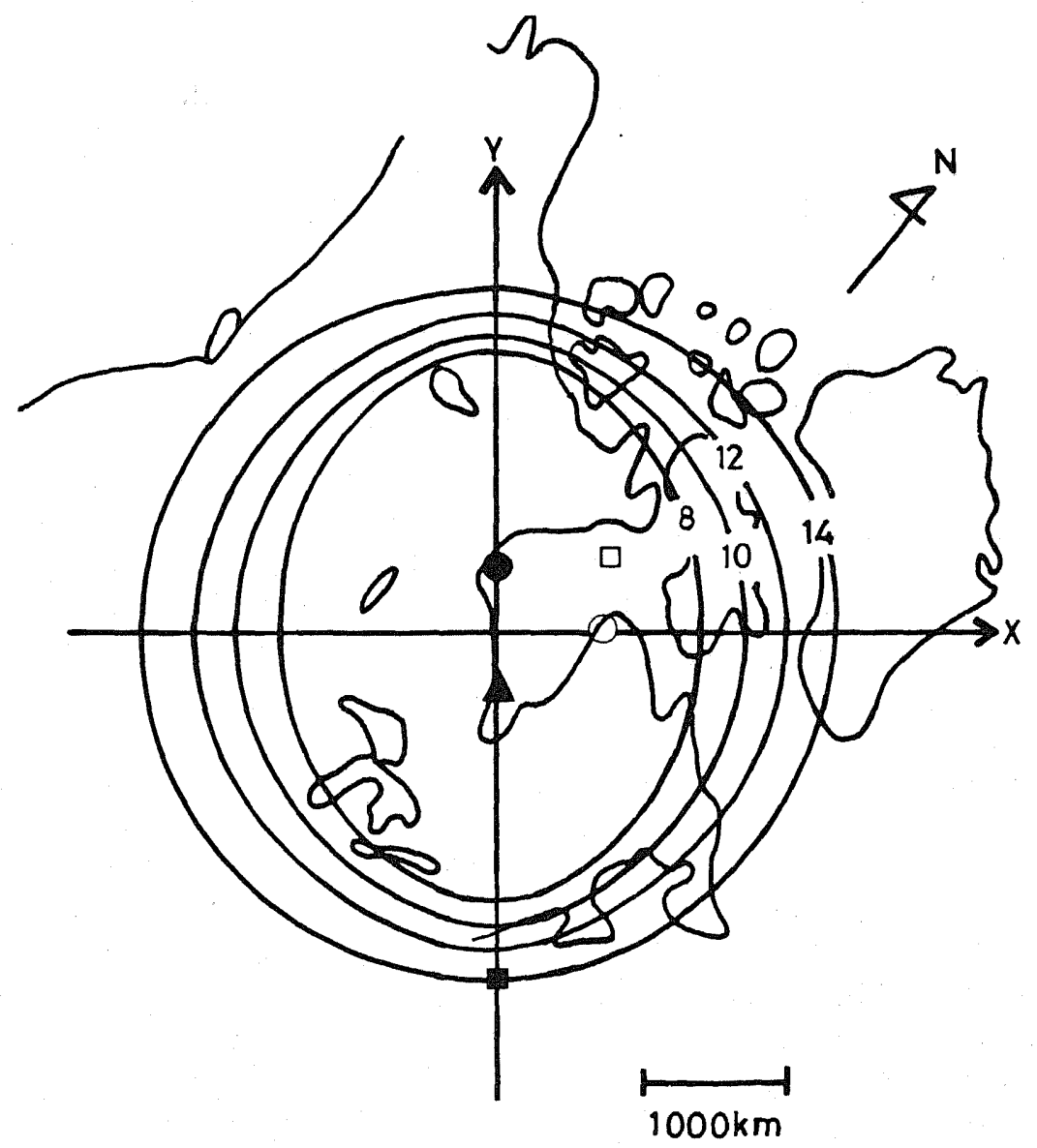

Fig. 12. Smoothed distribution of ice sheet used in this study. The numbers represent $\times 1,000$ years B.P. 


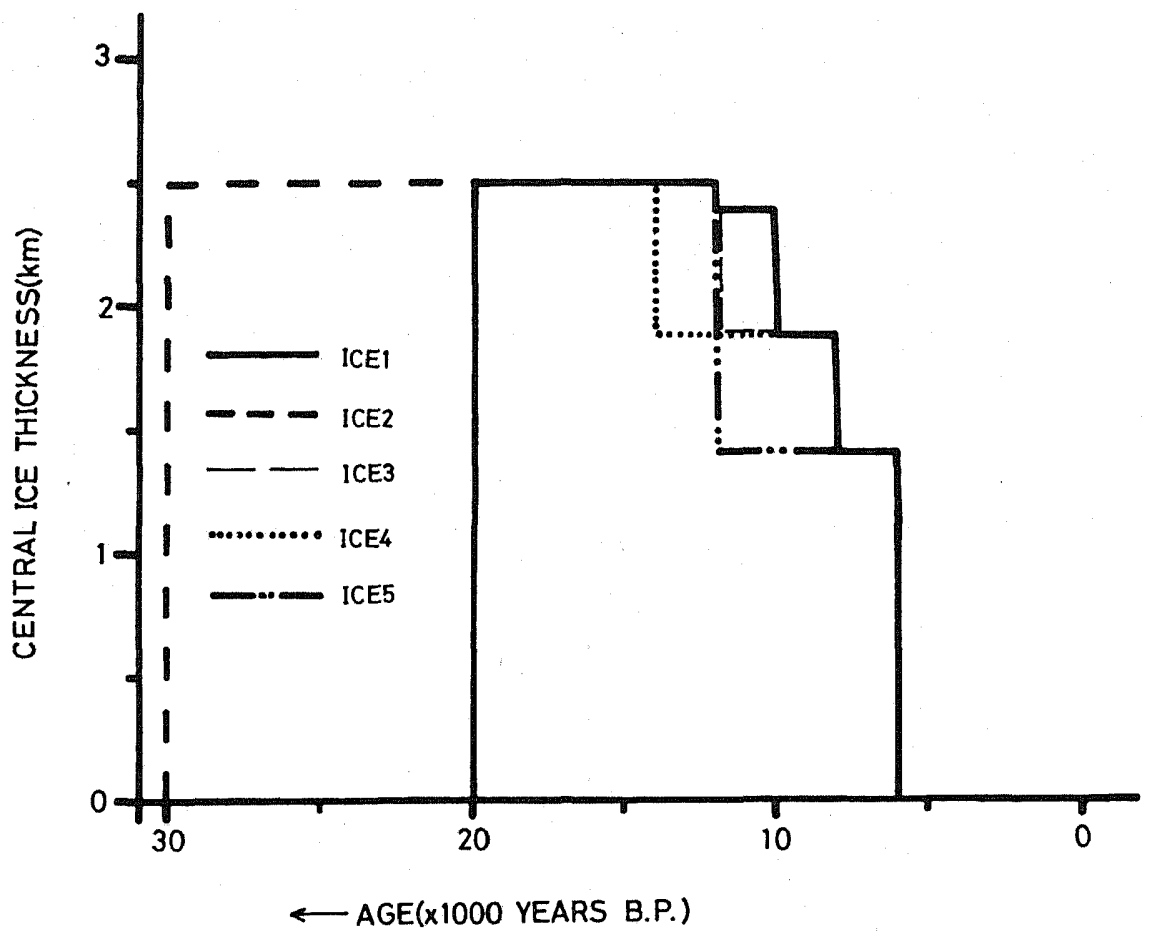

Fig. 13. Central ice thickness for each deglaciation history model. Areal extent for each model at each time is shown in Fig. 12.

areal extent of ice sheet at each stage is a simplified version of Prest's model (Prest, 1969). The maximum ice thickness is fixed to $2,500 \mathrm{~m}$ at 12,000 years B.P. as was calculated by PATERSON (1972). Before this time, the average maximum ice thickness is a constant equal to about $2,000 \mathrm{~m}$. We calculated the relative sea level variations for models ICE 1, 2, 3, 4, and 5 of deglaciation history (Fig. 13). The area that ice sheet occupied is the same for each deglaciation history model. But ice thickness at each time is different.

We solved Eq. (3.42) using a finite difference method. Figure 14 shows the relative sea level variations for models ICE 1, 2, 3, 4, and 5 of deglaciation history (Fig. 13). In this figure, the quantity $D$ in Eq. (3.36) is tentatively fixed at $1.7 \times$ $10^{12} \mathrm{~cm}^{2} / \mathrm{sec}$. This value corresponds to $A H^{5}=125 \mathrm{~cm}^{8} \cdot \mathrm{sec}^{5} \cdot \mathrm{g}^{-3}$ in Eq. (3.40). In Fig. 14, the theoretical free-air gravity anomalies are also shown for Cape Henrietta Maria and Southampton Island. The theoretical free-air gravity anomalies at the Brigantine almost vanish for all the models. Figure 14 shows that the postglacial relative sea level patterns do not depend significantly on the deglaciation history in the glaciated region. In contrast to this, the relative sea level at Brigantine shows a remarkable change if the deglaciation history is given by models ICE 3,4 , and 5 . 

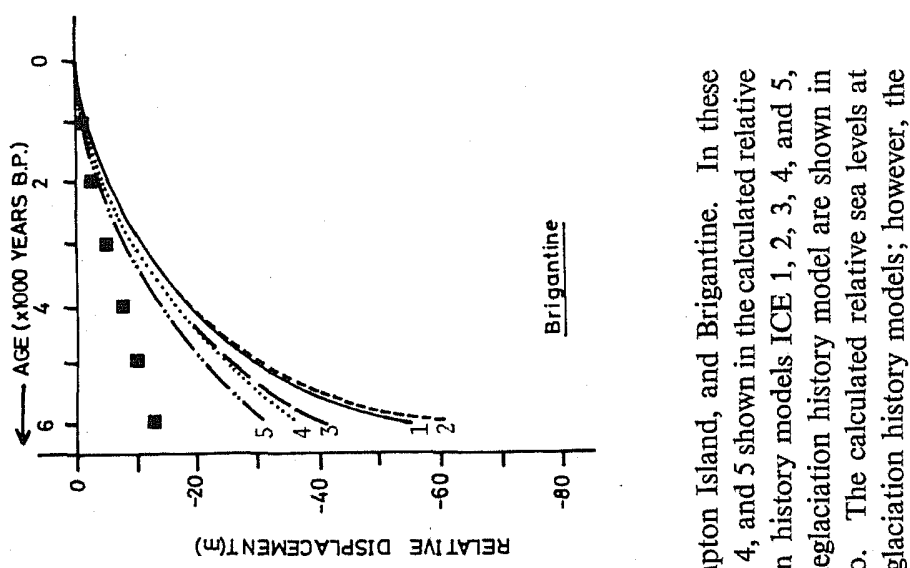

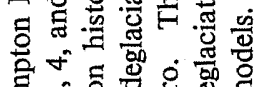

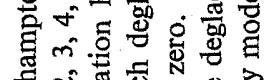

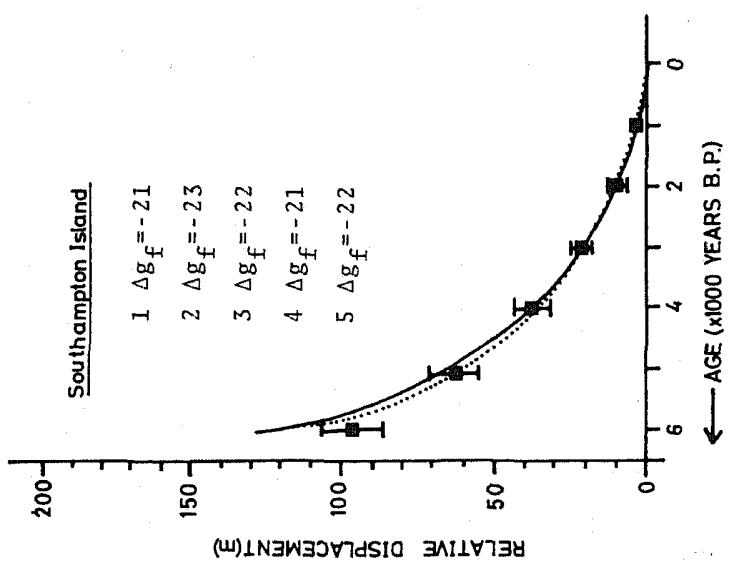

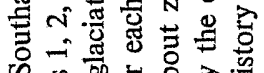

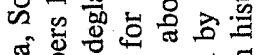

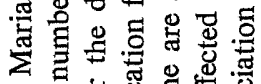

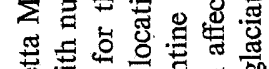

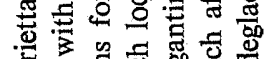

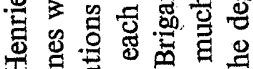

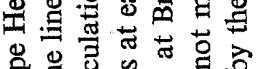

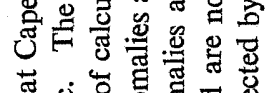

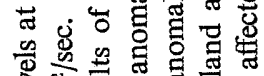

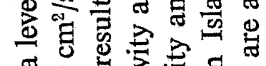

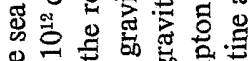

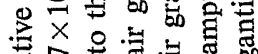

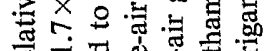

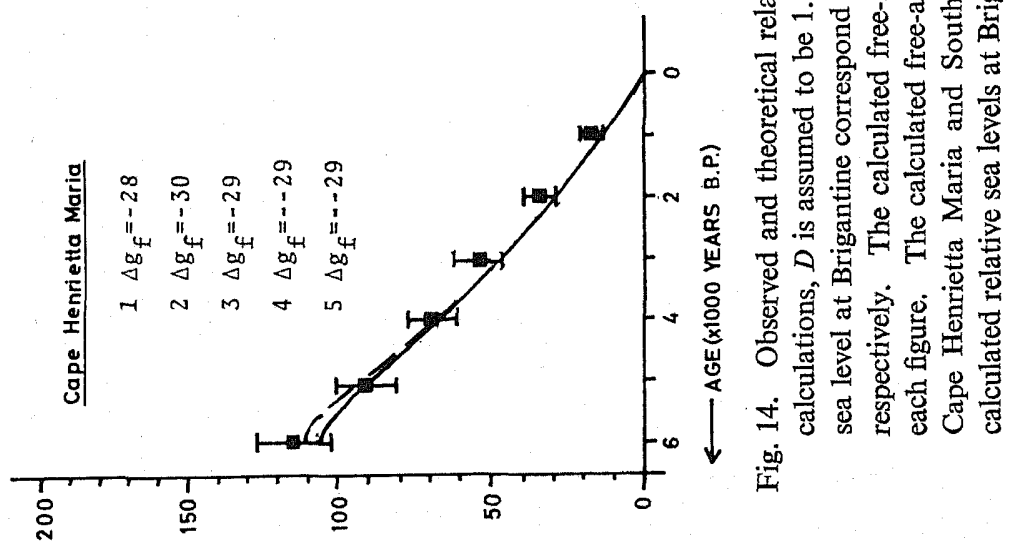

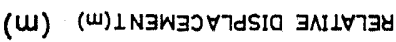



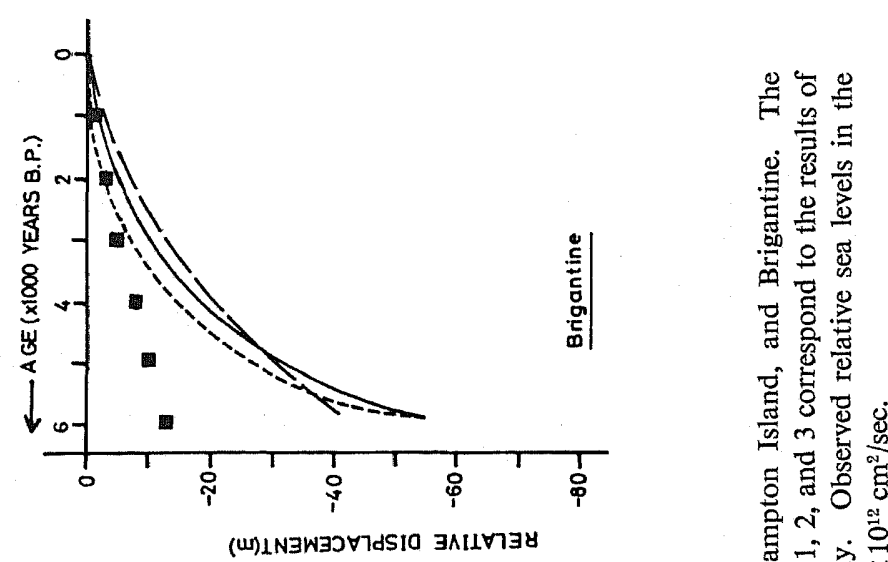

ํํำ

焉的家文

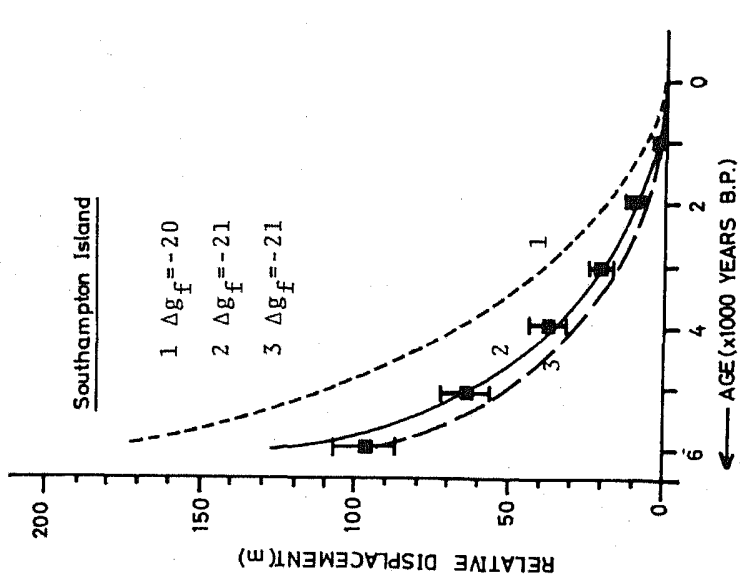

ह

当割

曾

$\sum \frac{\mathrm{d}}{0}$

焉 品

영을 융

岌

요 - 으응

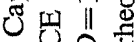

त $=0$ ?

曲哭

르을

宓

. 苟 矛守

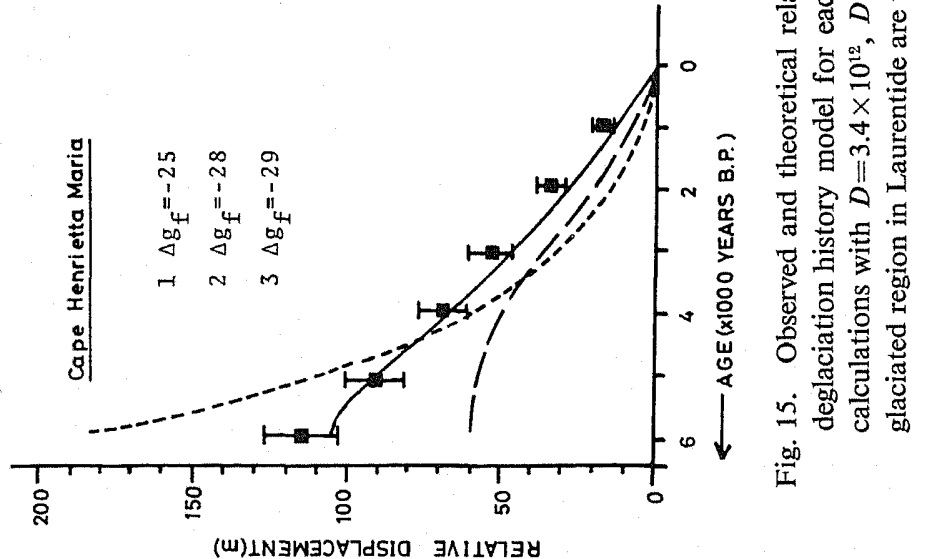



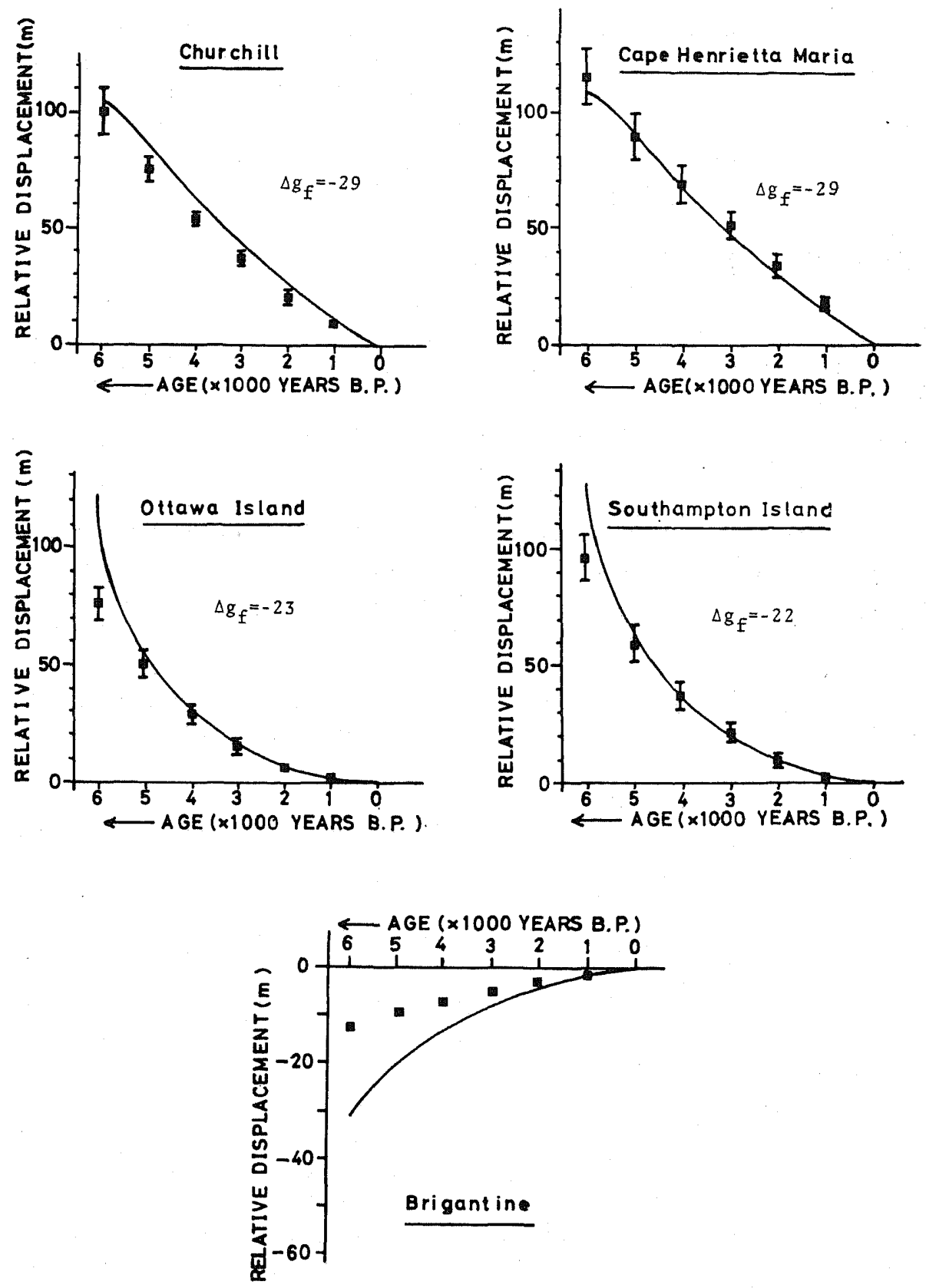

Fig. 16. Observed and theoretical relative sea levels at Cape Henrietta Maria, Churchill, Ottawa Island, Southampton Island, and Brigantine. The deglaciation history model is ICE 5 and $D=1.7 \times 10^{12} \mathrm{~cm}^{2} / \mathrm{sec}$. The calculated free-air gravity anomalies at each location are shown in each figure. 
The relative sea level variations for $D=1.0 \times 10^{12} \mathrm{~cm}^{2} / \mathrm{sec}$ and $3.4 \times 10^{12} \mathrm{~cm}^{2} /$ sec are shown in Fig. 15. This results in Fig. 15 show that the observed relative sea level and free-air gravity anomalies at Cape Henrietta Maria and Southampton Island are reproduced better by calculation for $D=1.7 \times 10^{12} \mathrm{~cm}^{2} / \mathrm{sec}$. The relative sea level variations at five locations for model ICE 5 are shown in Fig. 16, where $D$ is assumed to be $1.7 \times 10^{12} \mathrm{~cm}^{2} / \mathrm{sec}$.

\subsection{Implications of the calculation and discussion}

\subsubsection{Relative sea level variation and free-air gravity anomaly}

It has been shown that the observed relative sea level in the glaciated region is well explained by the power-law creep flow of $n=3$ with $D=1.7 \times 10^{12} \mathrm{~cm}^{2} / \mathrm{sec}$ (Fig. 14 and Fig. 16). The free-air gravity anomaly corresponding to the present remaining uplift is also consistent with the same model. Clearly our model fits the observations in the glaciated region of Laurentide better than the previous models of Peltier et al. (1978) and Clark et al. (1978). Unfortunately the calculated relative sea level in Brigantine is about three times larger than that observed in the peripheral region; the fit, however, is better than that by PELTIER et al. (1978) and CLARK et al. (1978). Forebulge regions such as Brigantine are located on the boundary between ocean and continent. Considering the temperature difference between oceanic and continental upper mantle (MERCIER and CARTER, 1975), this misfit may be improved (in preparation). Namely reasonable lateral heterogeneity of the rheological structure between oceanic and continental upper mantle may improve this misfit.

\subsubsection{Average temperature}

From the viewpoint of material science, the constitutive equation of mantle material is written as

$$
\dot{\varepsilon}_{i j}=\frac{A_{1}}{T} \exp \left(-\frac{E^{*}+P V^{*}}{R T}\right) J_{o} \sigma_{i j}{ }^{\prime},
$$

where $T, E^{*}, V^{*}, R, J_{\sigma}$, and $A_{1}$ are temperature, activation energy, activation volume, gas constant, second invariant of the deviatoric stress tensor, and preexponential constant, respectively (WEERTMAN, 1970). The parameter $A$ that has been introduced in Eq. (3.2) is given by

$$
A=\frac{A_{1}}{T} \exp \left(-\frac{E^{*}+P V^{*}}{R T}\right) .
$$

We have estimated the coefficient $D$ in Eq. (3.39) as $D=1.7 \times 10^{12} \mathrm{~cm}^{2} / \mathrm{sec}$ so as to fit the observed relative sea level data in Laurentide. If $A$ is independent of the depth, $D$ is proportional to $A$ as is shown in (3.40). Although this assumption may not hold very well, we may use the resultant relation if $A$ is regarded as a suitable average. The value of $A H^{5}$ is $125 \mathrm{~cm}^{8} \cdot \mathrm{sec}^{5} \cdot \mathrm{g}^{-3}$ for $D=1.7 \times 10^{12}$ $\mathrm{cm}^{2} / \mathrm{sec}$, when $\rho$ and $g$ are assumed to $b e 3.3 \mathrm{~g} / \mathrm{cm}^{3}$ and $980 \mathrm{~cm} / \mathrm{sec}^{2}$, respectively.

If the rheological parameters obtained by KARATO (1977) and KIRBY and 
Table 2. Rheological parameters used in this study.

\begin{tabular}{lccc}
\hline & $A_{1}\left(\mathrm{~cm}^{3} \cdot \mathrm{sec}^{5} \cdot \mathrm{g}^{-3} \mathrm{~K}\right)$ & $E^{*}(\mathrm{kcal} / \mathrm{mol})$ & $V^{*}\left(\mathrm{~cm}^{3} / \mathrm{mol}\right)$ \\
\hline KIRBY and RALEIGH (1973) & $7.9 \times 10^{-16}$ & 96 & 11 \\
KARATO (1977) & $5.4 \times 10^{-13}$ & 127 & 14 \\
\hline
\end{tabular}

Table 3. Geophysical parameters obtained in this study.

\begin{tabular}{ccccc}
\hline & $A\left(\mathrm{~cm}^{3} \cdot \mathrm{sec}^{5} \cdot \mathrm{g}^{-3}\right)$ & $\tilde{\sigma}_{x z}{ }^{\prime}(\mathrm{bar})$ & $\tilde{\dot{\varepsilon}}_{x z}\left(\mathrm{sec}^{-1}\right)$ & $\tilde{\eta}$ (poise) \\
\hline$H=200 \mathrm{~km}$ & $3.9 \times 10^{-35}$ & 4.5 & $7.0 \times 10^{-15}$ & $3.2 \times 10^{20}$ \\
$H=400 \mathrm{~km}$ & $2.4 \times 10^{-36}$ & 9.0 & $1.8 \times 10^{-15}$ & $2.6 \times 10^{21}$ \\
$H=600 \mathrm{~km}$ & $1.6 \times 10^{-37}$ & 13.5 & $7.8 \times 10^{-16}$ & $8.6 \times 10^{21}$ \\
\hline
\end{tabular}

RALEIGH (1973) (Table 2) are employed, the average temperatures turn out to be about $1,700 \mathrm{~K}$ and $1,500 \mathrm{~K}$, respectively. These estimates are almost independent of the thickness of the low viscosity layer, and are consistent with the geotherms in the earth's mantle obtained by MERCIER and CARTER (1975), CLARK and RiNGwood (1964), and AKImoto et al. (1976).

\subsubsection{Average strain rate and deviatoric stress}

Here we try to estimate the average strain rate over the thickness of low viscosity thin channel. In the thin channel viscosity model, average strain rate $\tilde{\dot{\varepsilon}}_{x z}$ and $\widetilde{\dot{\varepsilon}}_{y z}$ are approximated to be $\partial \tilde{u} / \partial z$ and $\partial \tilde{v} / \partial z$, respectively. Assuming that $A$ is constant, we average Eqs. (3.29) and (3.30) over $H$, as

$$
\begin{aligned}
& \frac{\partial \tilde{u}}{\partial z}=-\frac{A(\rho g H)^{3}}{2}\left[\left(\frac{\partial \zeta}{\partial x}\right)^{2}+\left(\frac{\partial \zeta}{\partial y}\right)^{2}\right] \frac{\partial \zeta}{\partial x} \\
& \frac{\partial \tilde{v}}{\partial z}=-\frac{A(\rho g H)^{3}}{2}\left[\left(\frac{\partial \zeta}{\partial x}\right)^{2}+\left(\frac{\partial \zeta}{\partial y}\right)^{2}\right] \frac{\partial \zeta}{\partial y} .
\end{aligned}
$$

The distribution of the present displacement is rather smooth, and the magnitude of $\partial \zeta / \partial x$ and $\partial \zeta / \partial y$ are represented by a typical value of about $9 \times 10^{-5}$. Putting these values into (3.50) and (3.51), we have $2.8 / H^{2} \mathrm{sec}^{-1}$ for the magnitude of $\tilde{\dot{\varepsilon}}_{x z}$ and $\tilde{\dot{\varepsilon}}_{y z}$, where $H$ denotes the relaxation thickness in $\mathrm{cm}$. Given the relation of (3.2) and that the magnitude of $\tilde{\dot{\varepsilon}}_{x z}$ and $\tilde{\dot{\varepsilon}}_{y z}$ is about $2.8 / \mathrm{H}^{2} \mathrm{sec}^{-1}$, we have $0.22 \mathrm{H}$ bar for the magnitude of $\tilde{\sigma}_{x z z}{ }^{\prime}$ and $\tilde{\sigma}_{y z}{ }^{\prime}$. The average strain rates $\dot{\varepsilon}_{x z}$ or $\dot{\varepsilon}_{y z}$, are estimated to be $7.0 \times 10^{-15}, 1.8 \times 10^{-15}$, and $7.8 \times 10^{-16} \mathrm{sec}^{-1}$ for $H=200,400$, and $600 \mathrm{~km}$, respectively. Corresponding average deviatoric stress $\tilde{\sigma}_{x z}{ }^{\prime}$ and $\tilde{\sigma}_{y z}{ }^{\prime}$ are estimated to be $4.5,9$, and 13.5 bars for $H=200,400$, and $600 \mathrm{~km}$, respectively (Table 3).

The results of laboratory creep experiments are shown on the plane of strain rate $\dot{\varepsilon}$ v.s. deviatoric stress $\sigma$ in Fig. 17 . In these data, Durham and Goetze (1977) obtain the strain rate for single crystal olivine at $1,300^{\circ} \mathrm{C}$. The experiment by Post (1977) is for dunite (dry and wet conditions) at $1,300^{\circ} \mathrm{C}$. These results satisfy the relation of $\dot{\varepsilon} \propto \sigma^{3}$. We have already obtained the strain rate and devia- 


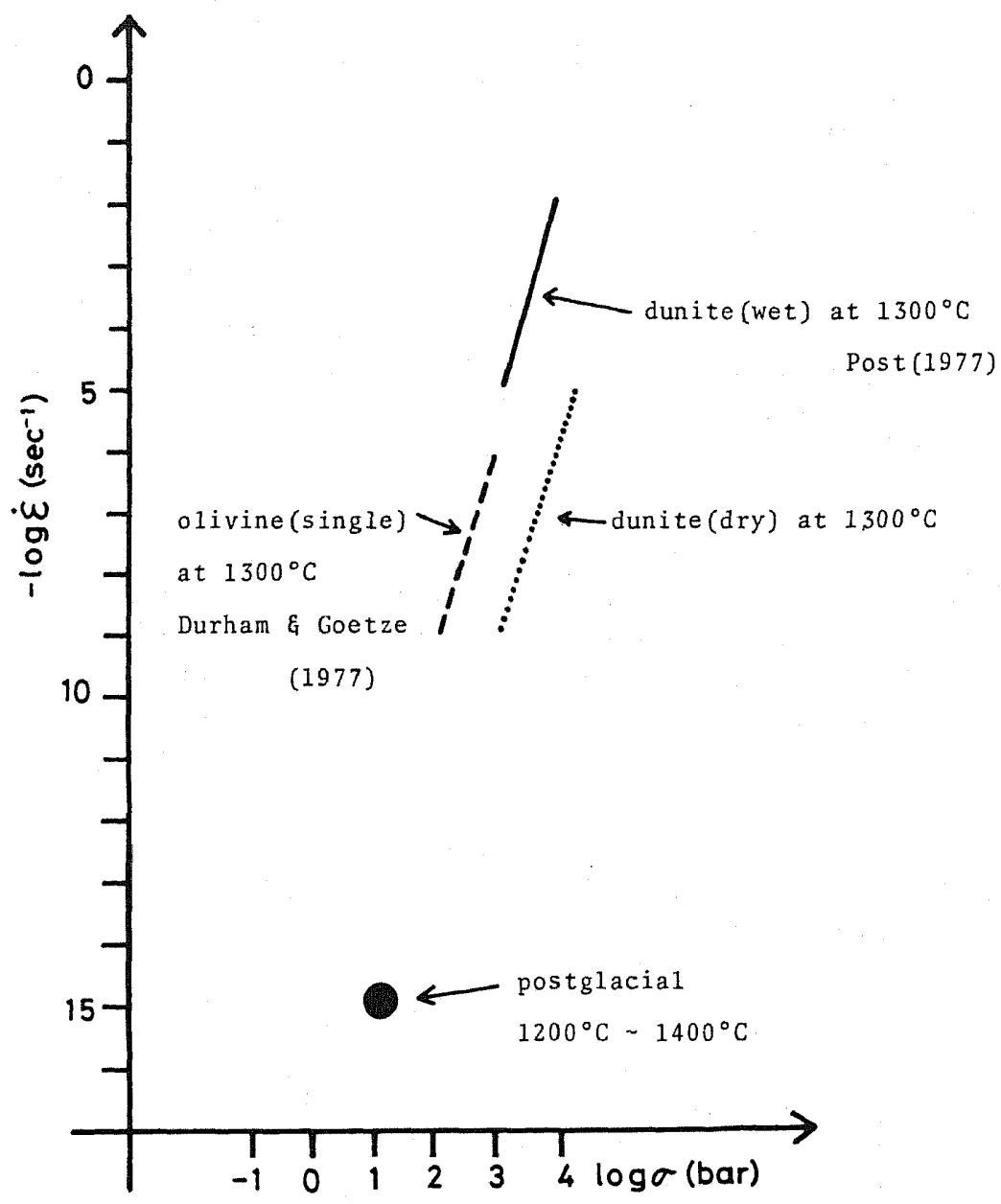

Fig. 17. Relation between strain rate and deviatoric stress. Experiemental results by DuRHAM and GOETZE (1977) and POST (1977) and results obtained in the present study are shown.

toric stress associated with postglacial rebound. This result is also plotted on the same plane of Fig. 17. It is interesting that our results are compatible with laboratory creep experiment despite quite large differences in strain rates. We recall that the average temperature, strain rate, and deviatoric stress obtained by the present analysis are $1,200^{\circ} \mathrm{C}$ to $1,400^{\circ} \mathrm{C}, 10^{-15} \mathrm{sec}^{-1}$, and 10 bars, respectively, while they are $1,300^{\circ} \mathrm{C}$, greater than $10^{-15} \mathrm{sec}^{-1}$, and 100 bars, respectively, for the laboratory experiments. Our results fall on the extrapolated line for dunite under dry conditions obtained by Post (1977).

3.4.4 Average viscosity

If $A$ is independent of depth, average viscosity is given from relation (3.2) as 


$$
\nu=\frac{\tilde{\sigma}_{x z}^{\prime}}{2 \tilde{\dot{s}}_{x z}}=\frac{1}{4 \tilde{\sigma}_{x z}{ }^{2}} \frac{1}{A} .
$$

Using the previously obtained result of $A H^{5}=125 \mathrm{~cm}^{8} \cdot \mathrm{sec}^{5} \cdot \mathrm{g}^{-3}$ and the estimate of deviatoric stress, we have $0.44 H^{3}$ poise for the average viscosity. The average viscosity is $3.2 \times 10^{20}, 2.6 \times 10^{21}$, and $8.6 \times 10^{21}$ poise, for $H=200,400$, and $600 \mathrm{~km}$, respectively (Table 3 ).

\subsubsection{The relation of vertical displacement and velocity}

The relation of $\dot{\zeta} \propto \zeta^{m}$ between displacement and velocity also holds for powerlaw creep flow in the thin channel viscosity model. Figure 18 shows the results of analysis for the power-law creep of $n=3$ at Cape Henrietta Maria and Southampton Island. The value of $m$ estimated for power-law creep is again 3 or 4 , similar to the results for linear analysis with Newtonian flow (Sec. 2). This confirms that the relation $\zeta \propto \zeta^{3-4}$ is realized regardless of the constitutive relation if the low viscosity is concentrated in a thin channel. In other words, the observed relation $\dot{\zeta} \propto \zeta^{3-4}$ in Laurentide and Fennoscandia has little relation to non-linearity of the rheological properties of the earth's mantle, in spite of early suggestions by PosT and GRIGGS (1973) and YoKOKURA and SArTo (1978).

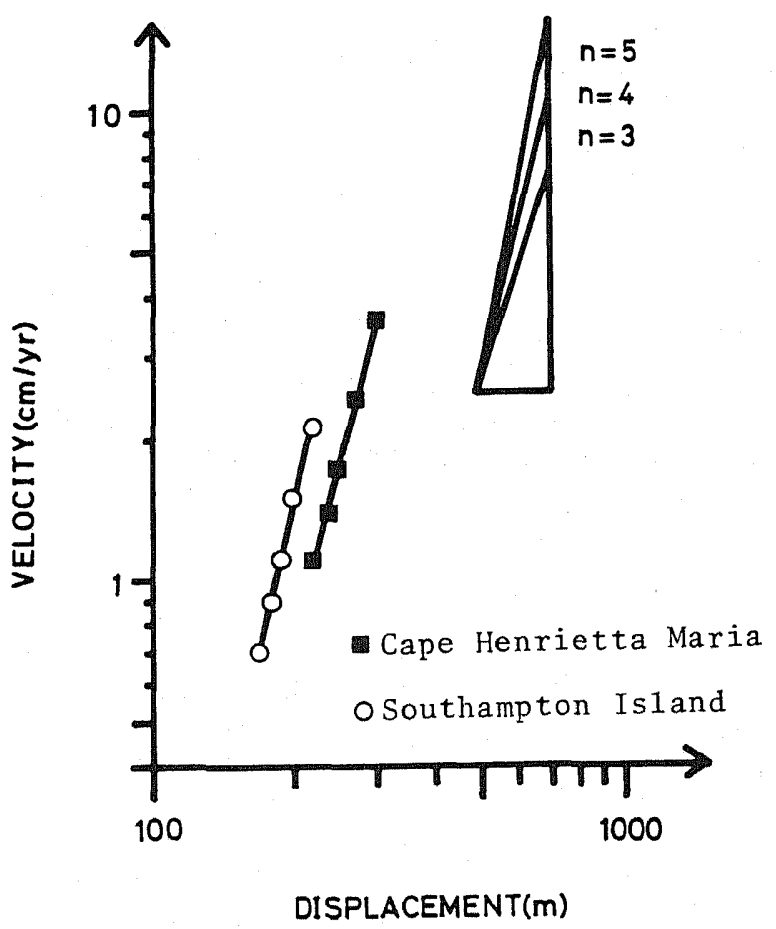

Fig. 18. The relation between calculated uplift rate and calculated remaining uplift. The remaining uplift and uplift rate are calculated based on the deglaciation history model ICE 5 and $D=1.7 \times 10^{12} \mathrm{~cm}^{2} / \mathrm{sec}$. 


\section{Conclusion}

According to linear analysis with a Newtonian rheology, an apparent viscosity derived from the observed relative sea level data is larger in the center of glaciated regions, such as Cape Henrietta Maria and Churchill, than those in the surrounding locations of Southampton Island and Ottawa Island. Quantitatively, the apparent viscosity in the central region is about ten times larger than that of the surrounding region. In other words, no viscosity model with a laterally homogeneous Newtonian rheology explains all the relative sea level data in Laurentide simultaneously. Late glacial peripheral uplift followed by subsidence does not seem to be a phenomenon that is explained only by the lower mantle viscosity of about $10^{22}$ poise. Therefore, there is no strong evidence supporting a lower mantle viscosity of about $10^{22}$ poise.

In order to clarify more quantitatively the reasons for non-uniform distribution of apparent viscosity, we have tried to make an analysis with a power-law creep theology of $n=3\left(\dot{\varepsilon} \propto \sigma^{3}\right)$ in a thin channel viscosity model. This analysis satisfactorily explains the observed relative sea level data, as well as the free-air gravity anomalies in the glaciated region in Laurentide.

Post and Griggs (1973) and YoKoKura and SAITo (1978) attributed the relation $\dot{\zeta} \propto \zeta^{3-4}$ observed in Laurentide and Fennoscandia to the non-linearity of the constitutive relation of the mantle material. However, their interpretation turns out to be inadequate. The non-linearity between $\zeta$ and $\dot{\zeta}$ reflects the concentration of low viscosity into a thin channel asthenosphere, regardless of the constitutive equation. Such a viscosity structure is consistent with the model that was suggested by YoKoKuRA (1979), based on the dip angle of the descended slabs.

Summarizing all these results, we propose the following rheological structure of the earth's mantle: the upper mantle flow is governed by the power-law creep with $n=3\left(\dot{\varepsilon} \propto \sigma^{3}\right)$. The lower mantle viscosity is higher than $10^{24}$ poise, so that no significant flow takes place there. The analysis gives reasonable values for the average temperature, strain rate, and deviatoric stress associated with postglacial rebound. The result of the present analysis thus makes the presence of whole mantle convection suspicious.

I would like to thank Prof. K. Kobayashi for his continuous support. I would like to thank Prof. Y. Ida for his helpful suggestions and discussions in this study, and for his critical reading of the manuscript. I would also like to thank Dr. S. Karato for his helpful discussions. I am much indebted to the Japan Society for the Promotion of Sciences for the post-doctoral fellowship which has made it possible for me to complete this study.

\section{Appendix. Some Analytical Solutions for $\partial \zeta / \partial t=(\partial / \partial x)(\partial \zeta / \partial x)^{3}$}

There are some analytical solutions for the following nonlinear equation:

$$
\frac{\partial \zeta}{\partial t}=\frac{\partial}{\partial x}\left(\frac{\partial \zeta}{\partial x}\right)^{3}
$$


The equation is written in the following form:

$$
\frac{\partial \zeta}{\partial t}=3\left(\frac{\partial \zeta}{\partial x}\right)^{2} \frac{\partial^{2} \zeta}{\partial x^{2}}
$$

Therefore, the analytical solution for the following form was investigated:

$$
\frac{\partial \zeta}{\partial t}=\left(\frac{\partial \zeta}{\partial x}\right)^{2} \frac{\partial^{2} \zeta}{\partial x^{2}}
$$

Though there are no physical meanings, we made a transformation of variables as below:

$$
\eta=x^{\alpha}\left(t+t_{0}\right)^{\beta},
$$

where $t_{0}$ is a constant value. Then we sought a solution of the following type:

$$
\zeta(x, t)=\left(t+t_{0}\right)^{m} f(\eta) \text {. }
$$

By using (A.3) and (A.4), (A.2) is written in the following form:

$$
\left(m f+\beta \eta \frac{\mathrm{d} f}{\mathrm{~d} \eta}\right)=\frac{\left(t+t_{0}\right)^{2 m+1}}{x^{4}} \alpha^{3} \eta^{3}\left(\frac{\mathrm{d} f}{\mathrm{~d} \eta}\right)^{2}\left[(\alpha-1) \frac{\mathrm{d} f}{\mathrm{~d} \eta}+\alpha \eta \frac{\mathrm{d}^{2} f}{\mathrm{~d} \eta^{2}}\right] .
$$

If $\left(t+t_{0}\right)^{2 m+1} / x^{4}=\eta^{k}$, that is, $\alpha, \beta$, and $k$ satisfy the following relation:

$$
\begin{aligned}
& -4=\alpha k \\
& 2 m+1=\beta k .
\end{aligned}
$$

(A.2) is transformed into the following differential equation:

$$
\left(m f+\beta \eta \frac{\mathrm{d} f}{\mathrm{~d} \eta}\right)=\alpha^{3} \eta^{k+3}\left(\frac{\mathrm{d} f}{\mathrm{~d} \eta}\right)^{2}\left[(\alpha-1) \frac{\mathrm{d} f}{\mathrm{~d} \eta}+\alpha \eta \frac{\mathrm{d}^{2} f}{\mathrm{~d} \eta^{2}}\right] .
$$

In the case of $m=0, k=-2, \alpha=2$, and $\beta=-1 / 2$, (A.7) is expressed as

$$
-\frac{1}{2}=24\left[2 \eta \frac{\mathrm{d} f}{\mathrm{~d} \eta} \frac{\mathrm{d}^{2} f}{\mathrm{~d} \eta^{2}}+\left(\frac{\mathrm{d} f}{\mathrm{~d} \eta}\right)^{2}\right] \text {. }
$$

The Eq. (A.8) can be solved and the solution expressed as:

$$
\zeta(\eta)=\frac{1}{16 C_{1} \sqrt{3}}\left(\tan ^{-1} \sqrt{\frac{C_{1}-\eta}{\eta}}-\frac{\eta}{C_{1}} \sqrt{\frac{C_{1}-\eta}{\eta}}\right)+C_{2},
$$

where $C_{1}$ and $C_{2}$ are determined by boundary and initial conditions.

In the case of $m=-1 / 6, k=-4, \alpha=1$, and $\beta=-1 / 6,($ A.8) is written in the following form:

$$
-\frac{1}{6}\left(f+\eta \frac{\mathrm{d} f}{\mathrm{~d} \eta}\right)=\left(\frac{\mathrm{d} f}{\mathrm{~d} \eta}\right)^{2} \frac{\mathrm{d}^{2} f}{\mathrm{~d} \eta^{2}}
$$

Integrating (A.10), we find

$$
2\left(\frac{\mathrm{d} f}{\mathrm{~d} \eta}\right)^{3}+\eta f=C_{1}
$$


where $C_{1}$ is a constant of integration. Assuming that $\zeta=0$ and approximately $\partial \zeta / \partial x=0$ for $x= \pm \infty$, we get $C_{1}=0$. In such a case, the solution is expressed as

$$
f(\eta)=\frac{\eta_{0}^{2}}{4}\left[1-\left(\frac{\eta}{\eta_{0}}\right)^{4 / 3}\right]^{3 / 2},
$$

where $\eta_{0}$ is an integration constant. Outside $\eta=\eta_{0}, f(\eta)$ is zero. The region of $f(\eta) \neq 0$ spreads following the relation $x \propto \sqrt[6]{t+t_{0}}$. By using (A.12), $\zeta$ is expressed as

$$
\zeta(x, t)=\frac{\eta_{0}^{2}}{4 \sqrt[6]{t+t_{0}}}\left[1-\left(\frac{\eta}{\eta_{0}}\right)^{4 / 3}\right]^{3 / 2} .
$$

By using (A.13), velocity $v(x, t)$ is expressed as

$$
v(x, t)=-\frac{\eta_{0}{ }^{2}}{24\left(t+t_{0}\right)^{7 / 8}}\left[1-3\left(\frac{\eta}{\eta_{0}}\right)^{4 / 3}\right] \sqrt{1-\left(\frac{\eta}{\eta_{0}}\right)^{4 / 3}} .
$$

Putting $x=0$ into (A.13) and (A.14), the relation between displacement $\zeta$ and velocity $v$ is expressed as $v \propto \zeta^{7}$. By using transformation of variables, the analytical particular solution of $\partial \zeta / \partial t=(\partial / \partial x)\left[(\partial \zeta / \partial x)^{n}\right]$ can be given.

\section{REFERENCES}

Akimoto, S., M. AKaogi, K. KaWAda, and O. Nishizawa, Mineralogic distribution of iron in the upper half of the transition zone in the earth's mantle, in The Geophysics of the Pacific Ocean Basin and Its Margins, ed. G. H. Sutton, M. H. Manghnani, and R. Moberly, Geophys. Monogr. No. 19, pp. 235-251, American Geophysical Union, Washington, D.C., 1976.

ANDREws, J. T., Present and postglacial rates of uplift for glacial northern and eastern North America derived from postglacial uplift curves, Can. J. Earth Sci., 7, 703-715, 1970a.

ANDrews, J. T., A Geomorphological Study of Post-glacial Uplift with Particular Reference to Arctic Canada, Institute of British Geographers, London, 1970b.

ArTYushkov, E. V., On the isostatic equilibrium of the earth's crust, Geophys. J.R. Astron. Soc., 14, 251-260, 1967.

ArTYushkov, E. V., Rheological properties of the crust and upper mantle according to data on isostatic movement, J. Geophys. Res., 76, 1376-1390, 1971.

Cathles, L. M., The Viscosity of the Earth's Mantle, Princeton University Press, New Jersey, 1975.

CATHLES, L. M., Interpretation of postglacial isostatic adjustment phenomena in terms of mantle rheology, in Earth Rheology Isostasy and Eustasy, ed. N. A. Mörner, pp. 11-43, Chichester, Wiley, 1980.

Clark, J. A., W. E. Farrell, and W. R. Peltier, Global change in postglacial sea level: A numerical calculation, $Q$. Res., 9, 265-287, 1978.

Crark, S. P., Jr. and A. E. RINGWOOD, Density distribution and constitution of the mantle, Rev. Geophys., 2, 35-88, 1964.

DAvis, G. F., Whole mantle convection and plate tectonics, Geophys. J.R. Astron. Soc., 49, 459486, 1977.

Durham, W. B. and C. Goetze, Plastic flow single crystals of olivine: 1 . Mechanical data, $J$. Geophys. Res., 82, 5737-5753, 1977.

ELSASSER, W. M., P. Olson, and B. D. MARSH, The depth of mantle convection, J. Geophys. Res., 84, 147-155, 1979. 
FAIRBRIDGE, R. W., The Encyclopedia of Geomorphorogy, Reinhold Book Company, New York, 1968.

Farrell, W. E. and J. A. Clark, On postglacial sea level, Geophys. J. R. Astron. Soc., 46, 647667, 1976.

HAGER, B. H. and R. J. O'CONNELL, Subduction zone dip angles and flow driven by plate motion, Tectonophysics, 50, 111-133, 1978.

HAGER, B. H. and R. J. O'CONNELL, Kinetic models of large-scale flow in the earth's mantle, J. Geophys. Res., 84, 1031-1048, 1979.

Haskell, N. A., The motion of a viscous fluid under a surface load 1, Physics, 6, 265-269, 1935.

HASKell, N. A., The motion of a viscous fluid under a surface load 2, Physics, 7, 56-61, 1936.

KARATo, S., Rheological properties of the materials composing the earth's mantle, $\mathrm{Ph}$. $\mathrm{D}$. thesis, Univ. Tokyo, 1977.

KAULA, W. M., Global gravity and tectonics, in The Nature of the Solid Earth, ed. E. C. Robertson, pp. 385-405, McGraw-Hill, New York, 1972.

KIRBY, S. H. and C. B. RALEIGH, Mechanism of high-temperature, solid-state flow in minerals and ceramics and their bearing on the creep behavior of the mantle, Tectonophysics, 19, 165195, 1973.

LliboutRY, L. A., Rheological properties of the asthenosphere from Fennoscandia data, $J$. Geophys. Res., 76, 1433-1446, 1971.

MCCoNNELL, R. K., Isostatic adjustment in a layered earth, J. Geophys. Res., 70, 5171-5188, 1965.

MCConNeLL, R. K., Viscosity of the mantle from relaxation time spectra of isostatic adjustment, J. Geophys. Res., 73, 7089-7105, 1968.

MerCIER, J. C. and N. L. CARTER, Pyroxene geotherms, J. Geophys. Res., 64, 3346-3362, 1975.

MÖRNER, N. A., The late quaternary history of Kattegatt sea and the Swedish coast, deglaciation, shorelevel displacement, chronology, isostasy and eustasy, Sveriger Geologiska Undersokning, C-640, 404-453, 1969.

Paterson, W. S. B., Laurentide ice sheet: Estimated volumes during late Wisconsin, Rev. Geophys. Space Phys., 10, 885-917, 1972.

PeltiER, W. R., Glacial-isostatic adjustment-II. The inverse problem, Geophys. J. R. Astron. Soc., 46, 669-705, 1976.

Peltier, W. R., Ice sheets, oceans, and the Earth's shape, in Earth Rheology Isostasy and Eustasy, ed. N. A. Mörner, pp. 45-63, Wiley, Chichester, 1980.

Peltier, W. R. and J.I. Andrews, Glacial isostatic adjustment-I. The forward problem, Geophys. J. R. Astron. Soc., 46, 605-646, 1976.

Peltier, W. R., W. E. Farrell, and J. A. Clark, Glacial isostasy and relative sea level: A global finite element model, Tectonophysics, 50, 81-110, 1978.

Peltier, W. R., P. WU, and D. A. YUen, The viscosities of the Earth's mantle, in Anelasticity in the Earth, ed. F.D. Stacey, M. S. Paterson, and A. Nicholas, Geodynamics Series, Vol. 4, pp. 59-77, American Geophysical Union, Washington, D.C., 1981.

Post, R. L., High-temperature creep of Mt. Burnet dunite, Tectonophysics, 42, 75-110, 1977.

Post, R. L. and D. T. Griggs, The earth's mantle: Evidence of non-Newtonian flow, Science, 181, 1242-1244, 1973.

PREST, V. K., Retreat of Wisconsin and recent ice in North America, Geological Survey of Canada Map No. 1257A Department of Energy, Mines, and Resonances, Canada, 1969.

SHEPARD, F. P., Thirty-five thousand years of sea level, in Essays in Marine Geology in Honor of K. O. Emery, ed. T. Clements, R. Stevanson, and D. Halmos, pp. 1-10, University of Southern California Press, Los Angels, 1963.

Stocker, R. L. and M. F. Ashry, On the rheology of the upper mantle, Rev. Geophys. Space Phys., 11, 391-426, 1973.

TAKeUCHI, H. and Y. HASEgaWA, Viscosity distribution within the earth, Geophys. J. R. Astron. Soc., 9, 503-508, 1965. 
VAN Bemmelen, R. W. and H. P. Berlage, Versuch einer mathematischen Behandlung geotectonisher Bewegunger unter besonderer Berucksichtigung der Undationstheorie, Gerlands Beitr. Geophys., 43, 19-55, 1935.

WALcort, R. I., Isostatic response to loading of the crust in Canada, Can. J. Earth Sci., 7, 716727, 1970a.

WaLcotT, R. I., Flexural rigidity, thickness and viscosity of the lithosphere, J. Geophys. Res., 75, 3941 -3954, 1970 b.

WaLcotr, R. I., Past sea levels, eustasy and deformation of the earth, Q. Res., 2, 1-14, 1972a.

WALCOTT, R. I., Late Quaternary vertical movements in eastern America: Quantitative evidence of glacio-isostatic rebound, Rev. Geophys. Space Phys., 10, 849-884, 1972b.

WALCOTT, R. I., Structure of the earth from glacio-isostatic rebound, in Annual Reviews of the Earth and Planetary Science, ed. F. A. Donath, F. G. Stehli, and G. W. Wetherill, pp. 1537, Annual Reviews Inc., Palo Alto, California, 1973.

WALCOTT, R. I., Rheological models and observational data of glacio-isostatic rebound, in Earth Rheology Isostasy and Eustasy, ed. N. A. Mörner, pp. 3-10, Wiley, Chichester, 1980.

WeErTMAN, J., The creep strength of the earth's mantle, Rev. Geophys. Space Phys., 8, 145-168, 1970.

Wu, P. and W. R. Peltier, Viscous gravitational relaxation, Geophys. J. R. Astron. Soc., 70, $435-485,1982$.

YoKoKuRA, T., Viscosity of the earth's mantle: Inference from dynamical support of decending slabs and other geophysical evidences, Ph. D. thesis, Univ. Tokyo, 1979.

YokokuRA, T. and M. SArto, Viscosity of the upper mantle as non-Newtonian fluid, J. Phys. Earth, 26, 147-166, 1978. 